PHYSICAL MECHANISMS OF CELL REARRAGEMENTS: FROM

TISSUE LIQUIDITY TO ARTIFICIAL ORGAN STRUCTURES

\author{
A Dissertation \\ Presented to \\ the Faculty of the Graduate School \\ University of Missouri-Columbia \\ In Partial Fulfillment \\ of the Requirements for the Degree \\ Doctor of Philosophy \\ by \\ KAROLY ROBERT JAKAB \\ Dr. Gabor Forgacs, Dissertation Supervisor \\ May 2006
}


The undersigned, appointed by the Dean of the Graduate School, have examined the dissertation entitled

PHYSICAL MECHANISMS OF CELL REARRAGEMENTS: FROM TISSUE LIQUIDITY TO ARTIFICIAL ORGAN STRUCTURES

Presented by Karoly Robert Jakab

a candidate for the degree of Doctor of Philosophy

and hereby certify that in their opinion it is worthy of acceptance.

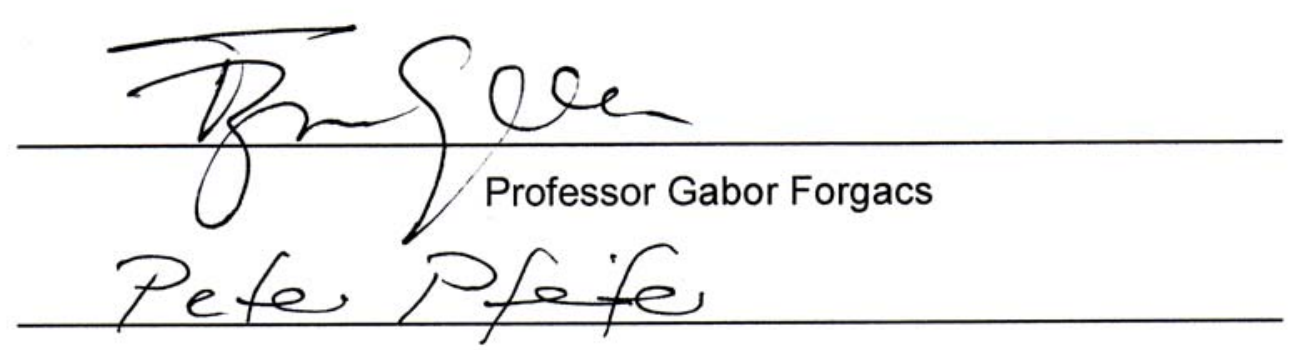

Professor Peter Pfeifer
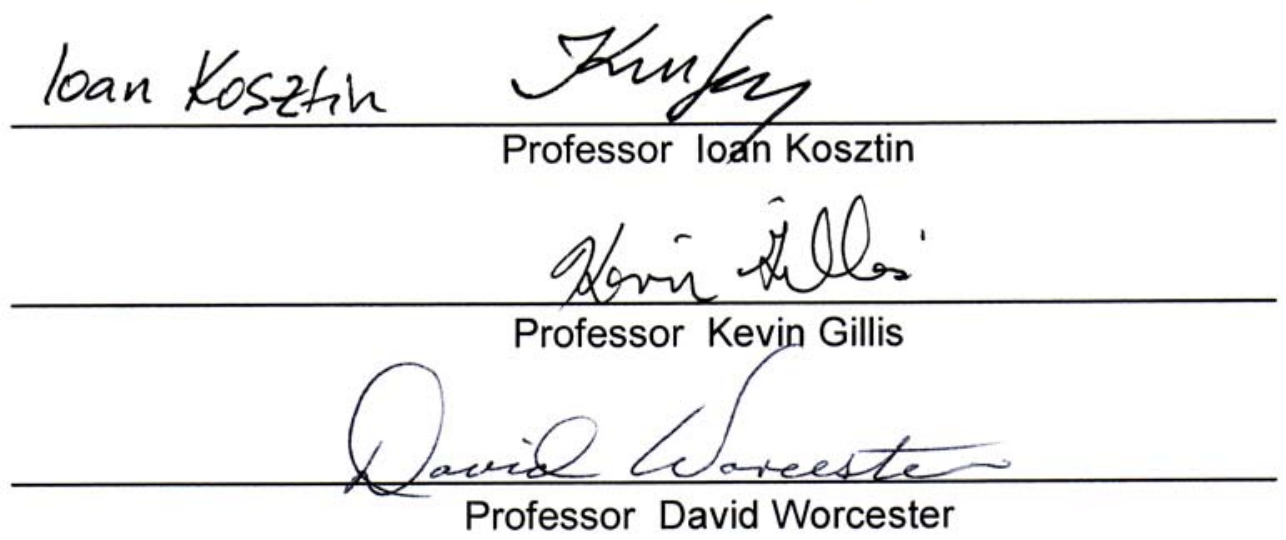
Szüleimnek 


\section{ACKNOWLEDGEMENTS}

First and foremost I would like to express my deepest gratitude to my advisor Dr. Gabor Forgacs, who gave me the opportunity to work and study in his research group. Sharing his insights, experience and knowledge he guided me through the research projects with great patience and kept me focused to seek the answers to the fundamental questions of biological physics we asked. I enjoyed his clear and concise explanations during endless discussions we had on the various research projects as well as his biological physics course. His honest opinion in appreciating my accomplishments or criticizing the failures helped establish an ideal supervisorstudent relationship I greatly benefited from. His style of supervision, professional attitude and teaching skills provided me with a role model in academics I will be proud to follow. I am also very grateful to him for allowing me to dedicate my time exclusively to research and supporting me as a full-time research assistant during my graduate studies. The countless opportunities he offered to present my research achievements at local, regional and national conferences helped me to develop my presentation skills; his constructive criticism and guidance in scientific writing were invaluable to bring this thesis to completion. Last but not least, despite his busy lifestyle he always found time to share with us outside the lab, where I had the chance to enjoy his companionship, great sense of humor and the manifestations of his culinary talents too.

Special thanks to Dr. Ioan Kosztin. Through his computational biological physics course taught with great enthusiasm and expertise, he sparked my interest 
in molecular dynamics simulations, luring me into a new field I am tempted to explore in the future.

I am grateful to Dr. Adrian Neagu who introduced me in computer simulations and gave a crash course in Matlab programming. His ideas and advices proved to be invaluable in developing the image and data analysis programs used in the present work.

My graduate committee members, Dr. Peter Pfeifer, Dr. Ioan Kosztin, Dr. Kevin Gillis and Dr. David Worcester are acknowledged for their discussions and useful advices.

I would like to express my gratitude to the former and present members of the Forgacslab, whom I had the pleasure working with: Basarab Hosu, Brook Damon, Dr. Francoise Marga, Dr. Balazs Hegedus, Mingzhai Sun and Octavian Doaga. They helped me design electronic devices, supplied tissue samples, collaborated on research projects, but more importantly they offered their friendship.

Dr. Russell Lansford from California Institute of Technology and the staff of the Molecular Cytology Core Facility are acknowledged for their assistance with confocal microscopy and fluorescent staining techniques.

I am grateful to Sam Potts and Roderick Schlotzhauer from the Machine Shop, who helped me with technical assistance whenever this work involved designing and building customized tools for measurements.

I would like to thank my wife Tunde for the encouragement, understanding and patience during the busy and stressful times I sometimes encountered. 
Last but not least, I would like to thank my parents Karoly and Ilona for their constant support, love and the sacrifices they brought to support me in working towards a degree in science. 


\section{Table of Contents}

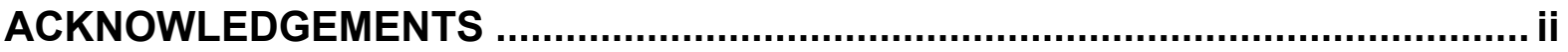

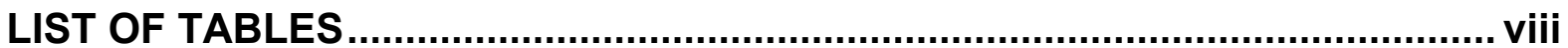

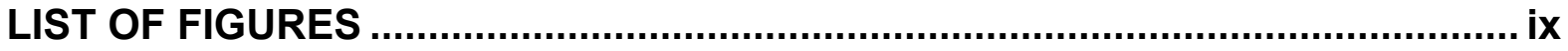

ABSTRACT

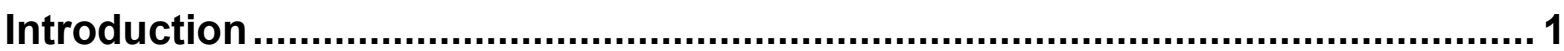

Tissue liquidity across scales: from the supercellular to the subcellular .......... 2

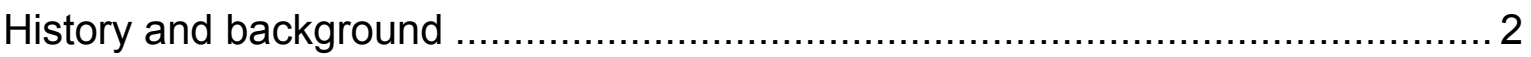

Direct observation of tissue liquidity on the cellular level ............................... 3

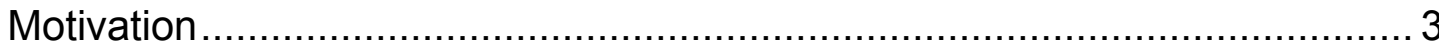

Experimental design and methods ................................................... 4

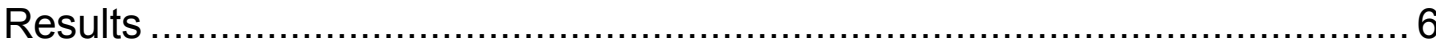

Strength of cellular adhesion depends on the integrity of the cytoskeleton ........9

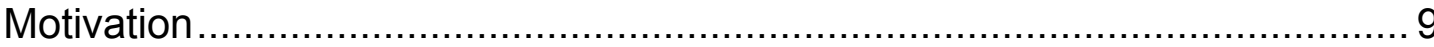

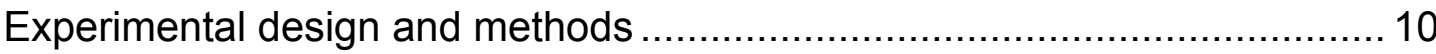

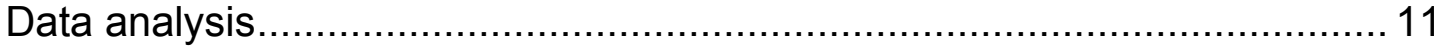

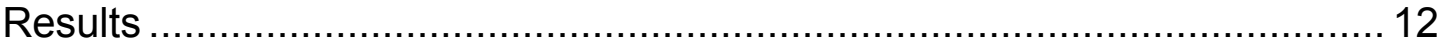

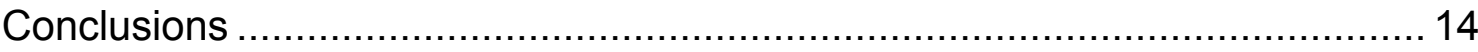

Engineering biological structures of prescribed shape using self assembling

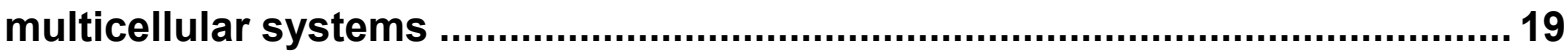

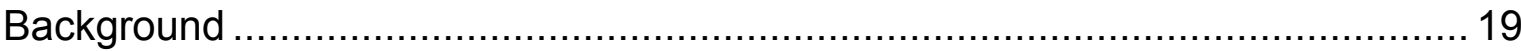

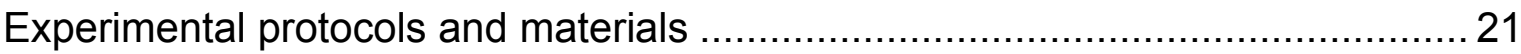

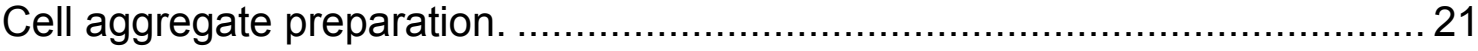




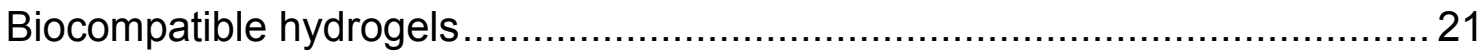

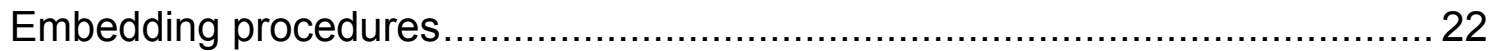

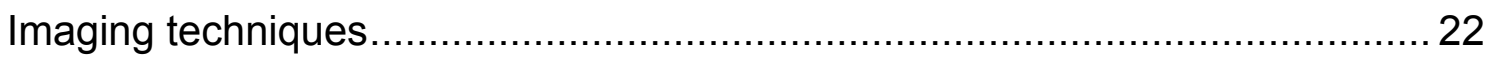

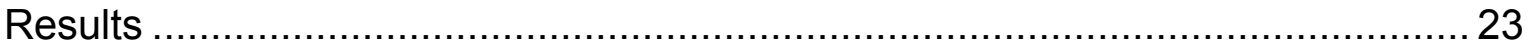

Experimental realization of the 3D structure ............................................... 23

The influence of the scaffold on 3D structure formation.................................24

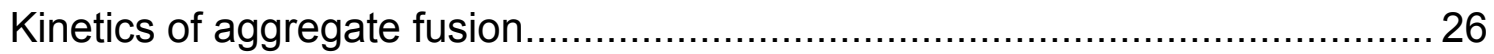

Optimization of fusion by the geometry of initial configuration: sheet formation 28 Fusion in three dimensions: cellular tube formation................................... 28

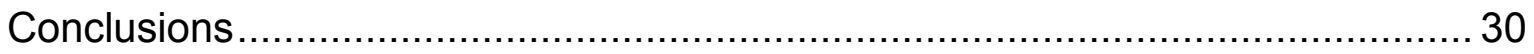

Organ printing: computer aided tissue engineering ...................................... 34

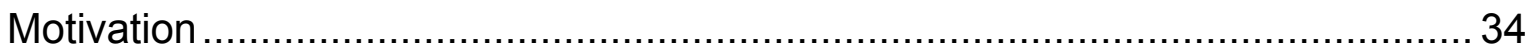

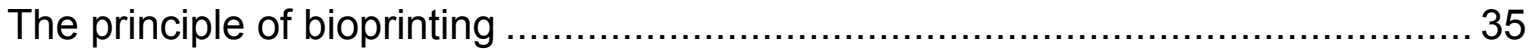

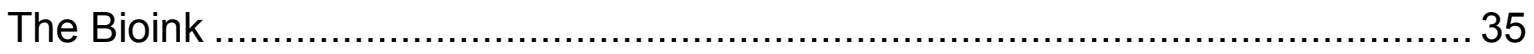

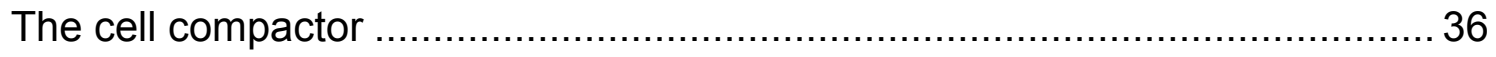

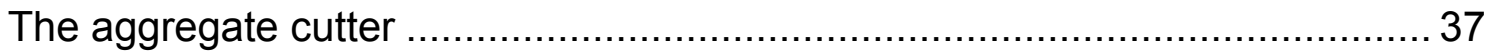

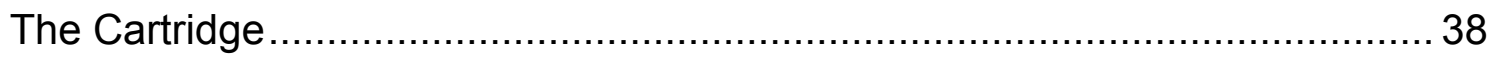

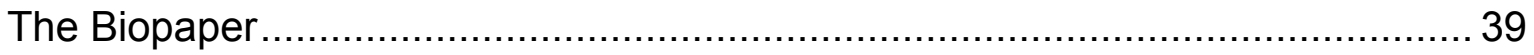

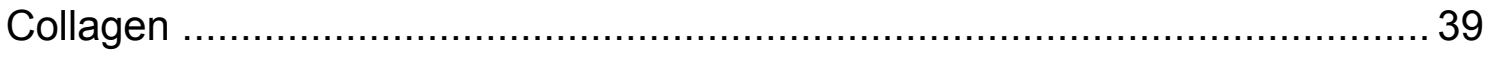

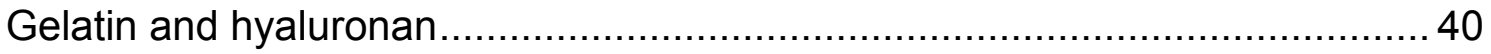

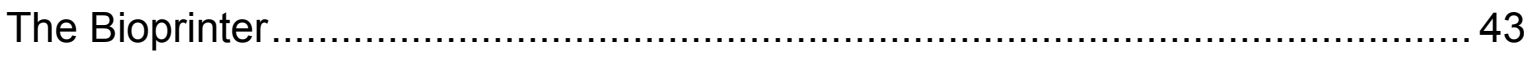

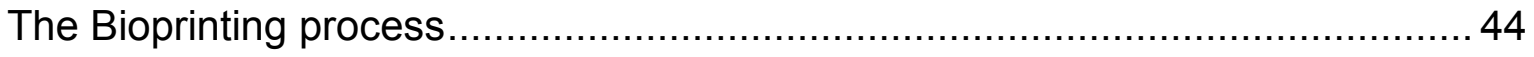

Functional living tissue structures created by bioprinting .............................. 47 


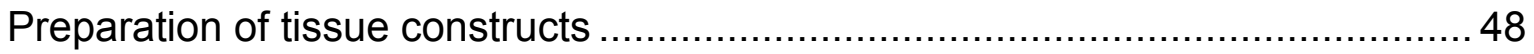

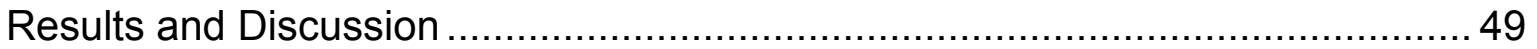

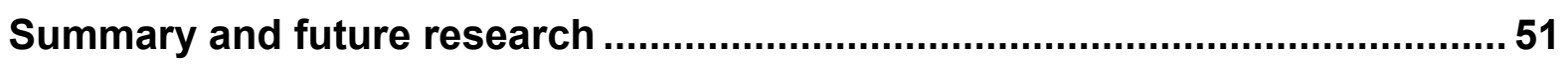

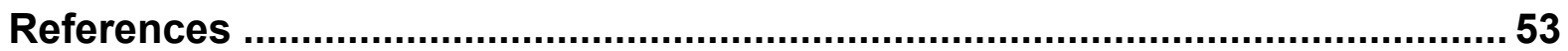

VITA 


\section{LIST OF TABLES}

Table 1. Relaxation times obtained from the double exponential fits to curves

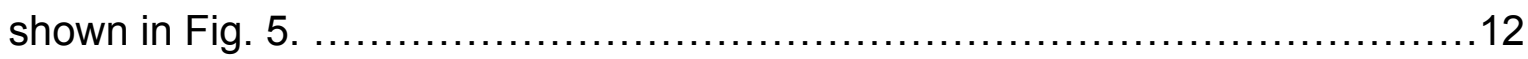




\section{LIST OF FIGURES}

Figure 1. Parallel plate compression apparatus for kinetic assays ................. 5

Figure 2. Direct observation of the individual cell movements ................. 7

Figure 3. Variations in individual cell shape during compression experiments

Figure 4. Parallel plate compression apparatus used to measure tissue surface tensions

Figure 5. Force relaxation upon compression of $500 \mu \mathrm{m}$ diameter spherical aggregates of $\mathrm{N}$-cadherin expressing $\mathrm{CHO}$ cells

Figure 6. Dependence of tissue surface tension on latrunculin concentration .

Figure 7. Initial and final cell aggregate configurations using various biocompatible hydrogels

Figure 8. Dynamics of gel contraction

Figure 9. Time course of aggregate fusion for the $1.0 \mathrm{mg} / \mathrm{ml}$ collagen concentration

Figure 10. Sheet formation depends on the initial configuration

Figure 11. Two- and three-dimensional tissue structures

Figure 12. The process of bioprinting

Figure 13. The cell compactor

Figure 14. The aggregate cutter and its principle of operation

Figure 15. Bioink and cartridge

Figure 16. Time lapse studies of cell migration and gel degradation for the 
gelatin gels

Figure 17. Interplay of cell-gel affinity and gel degradation .................. 42

Figure 18. The bioprinter and the extruders mounted on the $Z$ assembly ...... 44

Figure 19. Matlab based software for controlling the printer .................... 45

Figure 20. Basic initial aggregate templates and their evolution in time ........ 47

Figure 21. Chicken cardiac myocyte sheet obtained by bioprinting ............ 50 


\title{
PHYSICAL MECHANISMS OF CELL REARRAGEMENTS: FROM TISSUE LIQUIDITY TO ARTIFICIAL ORGAN STRUCTURES
}

\author{
Karoly Robert Jakab \\ Dr. Gabor Forgacs, Dissertation Supervisor
}

ABSTRACT

Embryonic development represents a sequence of spectacular morphogenetic transformations involving intense cellular rearrangements. Although developmental patterning is under genetic control, a living organism acquires its final form through physical shape transformations, a particular one being based on the apparent liquid-like properties of tissues composed of adhesive and motile cells (e.g. embryonic tissues). The Differential Adhesion Hypothesis (DAH) provides the molecular basis for these properties, which in turn provide the biophysical basis for a number of morphogenetic processes (e.g. sorting, epithelial folding, convergent extension, etc.).

In the present study we exploit these self-organizing properties to build functional 3D tissue constructs of prescribed shape. We demonstrate that tissue liquidity manifests also on the cellular level; the force relaxation under constant strain proceeds similarly to the mechanisms encountered in true liquids. Employing tissue liquidity, spherical cell aggregates were embedded contiguously into biocompatible gels creating templates for geometric configurations encountered in living organisms. Depending on the properties of the gels and the initial 
arrangements, upon incubation the aggregates fused into toroidal, tubular and planar configurations. The lifetime of the experimentally observed constructs depends on the magnitude of cell-cell and cell-gel interactions, thus long-lived tissue structures can be built.

The results of these proof of concept experiments were employed in the development of a rapid prototyping technique, "bioprinting". Due to their liquid like properties aggregates can be regarded as "bioink" droplets. We developed a protocol and a patent pending cutting device to produce standard aggregate size and customized the hardware and software of the bioprinter to improve the accuracy of embedding. Primary cell cultures of different types were used as multicolor bioink to create functional, living tissue constructs mimicking their native histological arrangements.

Our experiments and modeling efforts represent a novel approach to tissue engineering, an important step toward building complex organ modules via biological self-assembly. 


\section{Introduction}

This research topic represents a novel approach in tissue engineering, incorporating biological, physical and technical knowledge in order to create three dimensional living biological structures with prescribed shape through a rapid prototyping method, "bioprinting". Beyond the printing technology that actually creates the initial geometry of the tissue construct it investigates the self organizing capacity of cells and tissues, the biological self assembly based on tissue liquidity.

This thesis has three closely connected chapters. The first chapter starts with a description of experiments and their interpretation testing the analogy between living tissues and viscoelastic liquids, and presents new findings on the "microscopic", cellular level of tissues supporting the liquid like behavior. The knowledge gained from these studies is used in the second chapter, presenting proof of concept experiments to validate tissue liquidity as the concept behind biological self assembly. Here cell-cell and cell-extracellular matrix interactions are studied and analyzed to gain knowledge about the particular aspects of self organization, to determine the key factors during structure formation. Finally, the printing technology is presented, introducing and describing the concepts of biopaper and bioink together with the principle of bioprinting. The tissue constructs built by the newly developed method are shown and their relevance in tissue engineering are discussed along with the main conclusions and the proposed future projects. 


\section{Tissue liquidity across scales: from the supercellular to the subcellular}

\section{History and background}

Embryonic development represents a sequence of spectacular morphogenetic transformations involving intense cellular rearrangements, through which a living organism acquires its final shape via growth, differentiation, adhesion and morphogenesis. Although genes set up the inherent physico-chemical properties of cells, extracellular matrices and tissues, physical mechanisms are required to assemble these entities into forms and shapes. One such mechanism is based on the apparent liquid properties of embryonic tissues.

A number of properties of such tissues can be explained by considering them as viscoelastic liquids. Excised irregular tissue fragments placed in a non-adhesive physiological environment round up into spherical aggregates, as liquid drops do in order to minimize their surface area with the surrounding medium [1]. The spreading of one tissue type on the surface of another one is frequently encountered in normal development $[2,3]$. In vitro studies revealed two distinct pathways that lead to the same tissue configuration: mutual envelopment and cell sorting. If two tissue fragments of different type are brought in contact, one will spread on the surface of another, until partially or completely engulfs its partner. This engulfment takes place even if the two tissues do not encounter each other in the course of normal development [4-7]. When the same tissues are dissociated into single cells then randomly combined to form a homogenous mixture, they sort out, and the final 
configuration becomes a "sphere-in-a-sphere"[8, 9]. The similarities between living tissues and immiscible liquids during cellular rearrangements led Steinberg to formulate the Differential Adhesion Hypothesis (DAH) $[4,6,10,11]$, which provides the molecular basis of this analogy, postulating that the liquid like properties arise from the large number of constituent cells possessing type dependent adhesion apparatus while being motile. The liquid like behavior of such cell populations implies the existence of surface and interfacial tensions generated by adhesive and cohesive interactions between the component subunits. Recent experiments have demonstrated that tissue surface tension is a well-defined intensive physical parameter, predicting cell sorting and mutual envelopment patterns, thus validating the hierarchical and transitive character of cell sorting [1, 12]. Computer simulations based on tissue liquidity and statistical mechanical models confirmed the predictions of the $\mathrm{DAH}[13,14]$.

\section{Direct observation of tissue liquidity on the cellular level}

\section{Motivation}

The DAH was formulated to offer a physical explanation of analogies between living tissues and immiscible liquids as mutual envelopment, tissue segregation and cell sorting. The previously described in vitro experiments as well as in vivo manifestations of tissue liquidity [15-17] represent liquid like global cellular or tissue rearrangements as a result of morphogenetic processes. The predictive power of DAH's lies in the differences in surface and interfacial tensions. 
Being an equilibrium property, surface tension itself does not reveal information about the individual cell kinetics and the time course of cell movements. In order to address this issue, we have to dissect the most conspicuous property of liquids, their ability to flow. In ordinary liquids the molecules are held together by Van der Vaals forces, the mobility is powered by thermal energy, with scale set by $k_{B} \cdot T$ ( $\mathrm{k}_{\mathrm{B}}$ - Boltzmann constant, $\mathrm{T}$ - temperature). In tissues the cells are bound by cell and surface adhesion molecules, their motion is due to metabolic energy with scale set by ATP hydrolysis. Furthermore, the movement of cells is mainly due to the directional polymerization and depolymerization of the cytoskeleton, thus it strongly depends on the integrity of the subcellular actin network.

To address the question of how movement on cellular scale gives rise to liquid-like patterns we set up a kinetic assay to follow and quantify the displacement of individual cells upon compression of an originally spherical cell aggregate (i.e. model tissue). We found it is not only the final post-compressed state that is liquidlike, but so is the movement of cells in the process through which this state is attained.

\section{Experimental design and methods}

We considered spherical cell aggregates as model tissues mimicking the shape a liquid droplet adopts on nonadhesive substrate under no external forces. Confluent Chinese hamster ovary $(\mathrm{CHO})$ cell cultures (a widely used and well characterized cell line) transfected stably with $\mathrm{N}$-cadherin (courtesy of A. Bershadsky, Weizmann Institute, Rehovot, Israel) were grown in DMEM (GIBCO/BRL) supplemented with 10\% Fetal Bovine Serum (U.S. Bio-Technologies, 
Pottstown, PA), $10 \mu \mathrm{g} / \mathrm{ml}$ penicillin, streptomycin, gentamicin, and kanamycin, 400 $\mu \mathrm{g} / \mathrm{ml}$ geneticin), were washed twice with Hanks' balanced salt solution (HBSS) containing $2 \mathrm{mM} \mathrm{CaCl}_{2}$, then treated for 10 min with trypsin $0.1 \%$ (diluted from $2.5 \%$ stock, GIBCO/BRL). Depleted cells were centrifuged at 2,500 rpm for 4 min (Fisher Centrific model 225) (approximately $900 \mathrm{~g}$ ). The resulting pellet was transferred into capillary micropipettes of $500 \mu \mathrm{m}$ diameter and incubated at $37^{\circ} \mathrm{C}$ with $5 \% \mathrm{CO}_{2}$ for 10 min until they recovered their adhesive connections. The firm cylinders of cells removed from the pipettes were cut into $500 \mu \mathrm{m}$ long fragments then incubated in 10 $\mathrm{ml}$ tissue culture flasks (Bellco Glass, Vineland, $\mathrm{NJ}$ ) with $3 \mathrm{ml}$ of DMEM on a gyratory shaker at $120 \mathrm{rpm}$ with $5 \% \mathrm{CO} 2$ at $37^{\circ} \mathrm{C}$ for $24-36 \mathrm{~h}$. This procedure reproducibly provides spherical aggregates of similar size (500 $\mu \mathrm{m}$ diameter). To monitor the individual cell rearrangements in tissues during force relaxation, $10 \%$ of

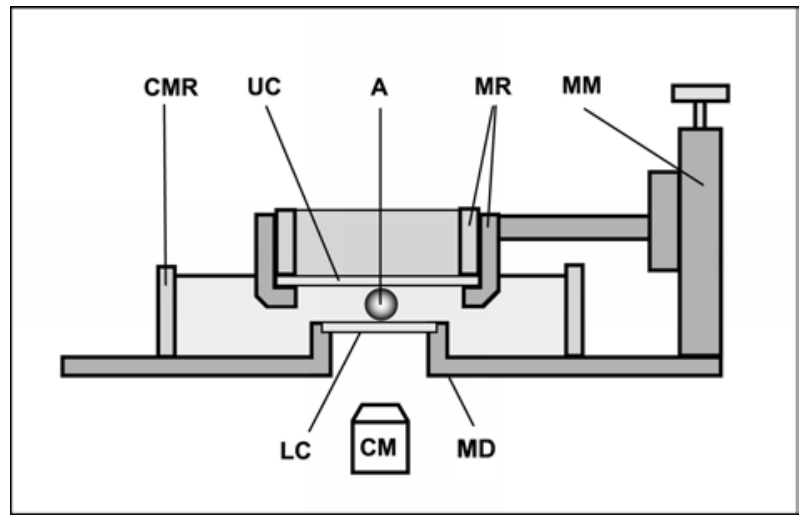

the cells were infected with histone binding H2B-YFP retrovirus, kindly provided by Russell Lansford (Beckman Institute at California Institute of Technology).

The kinetic assay was accomplished with a specifically designed parallel

Fig.1. Parallel plate compression apparatus for compression apparatus, shown in Fig. kinetic assays.

1. A spherical cell aggregate was compressed between two parallel glass plates (UC and LC) immersed in a pool of $\mathrm{CO}_{2}$ independent tissue culture medium, contained by the culture medium reservoir 
(CMR). The UC is mounted on a metallic ring (MR) on the $z$ directional micromanipulator $(\mathrm{MM})$ of $10 \mu \mathrm{m}$ resolution. The LC is positioned on the metallic disk (MD) that also holds the micromanipulator. The apparatus is mounted on the stage of an Olympus IX-70 microscope with confocal imaging attachment (CM), used to record individual cell trajectories during the force relaxation process. A 60-80 $\mu \mathrm{m}$ section of the aggregate's lower part was scanned in $2 \mu \mathrm{m}$ steps. Complete scans were taken in 2 minute time intervals up to one hour, being the typical time to reach an equilibrium state. The positions of the fluorescently labeled cells (relative to the centers of the two-dimensional sections), determined by superposition of bright field and confocal images, were stored and later used for the reconstruction of cell trajectories. Average total inward and outward displacements were calculated using 15-40 cells per depth range.

\section{Results}

A spherical liquid droplet or tissue fragment rounds up to minimize its interface in contact with the environment, thus any deformation of such a droplet would result in a change of the surface area. A true liquid modifies its surface area by migration of loosely bound molecules from bulk to the periphery, or vice versa, maintaining a constant surface density of subunits. In contrast, solids consisting of immobile atoms or molecules accomplish the surface change by stretching or compressing the bonds between component subunits, leading to a variable surface density. To determine which mechanism is responsible for the increase in surface area we used optical sectioning of the aggregates perpendicular to the compression axis, following the paths of fluorescent cells within different depths. 
Cell motility depends on the integrity of the cytoskeleton. The movement of cells is accomplished by directional polymerization and depolymerization of the actin network, thus the force relaxation is directly influenced by the actin content of the

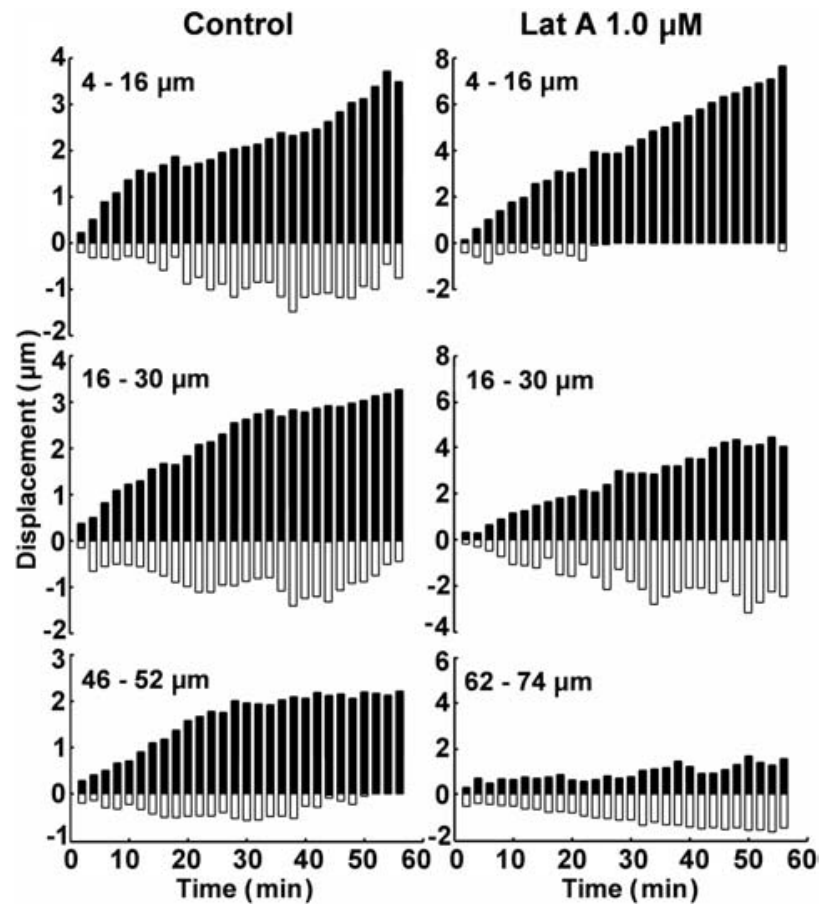

Fig.2. Direct observation of the individual cell movements. Filled and empty bars indicate mean outward and inward displacements, MRID and MRID, respectively. Left and right panels: cellular movements in control and Latrunculin A treated aggregates.

cells. We treated cell aggregates for 40 minutes with $1 \mu \mathrm{M}$ Latrunculin $\mathrm{A}$, the most actin specific agent, that inhibits polymerization by forming $1: 1$ complexes with the globular actin molecules [18].

Fig. 2 shows mean radial outward and inward displacements (MROD and MRID) within each layer of control and latrunculin treated aggregates. The distance range in the upper left corner of the subpanels is measured radially inward from the surface of the aggregates The mean values were calculated over all inward and outward moving fluorescent cells for a given layer. While $x-y$ positions were determined accurately based on the fluorescent contours of labeled nuclei, the accuracy of the $z$ coordinate was limited by the $2 \mu \mathrm{m}$ preset on the confocal microscope.

In absence of latrunculin the mean outward displacements increase gradually, and saturate after 50 minutes, indicating that cells move preferentially towards the 
periphery. This observation suggests that the relaxation to a new equilibrium state with increased area is achieved by a similar mechanism as in liquids. Moreover, displacements are the largest in the outer layer, decreasing towards the inside of the aggregate. Aggregates treated with latrunculin then compressed in regular medium exhibit a different behavior. As latrunculin diffuses out of the aggregate, the cells gradually regain their motility, thus the outer layers with enhanced motility will participate with larger displacements to relax the compression induced stress. Note the two fold increase in displacements in the 4-16 $\mu \mathrm{m}$ layer for the latrunculin treated aggregates in comparison with the same layer in the control samples. The latrunculin treatment shows another interesting property on the motility of cells: while in the outer layer the MROD dominates, in the inner layers the two displacements are comparable, the average "cell transport" characterized by the mean of MROD an MRID almost vanishes.
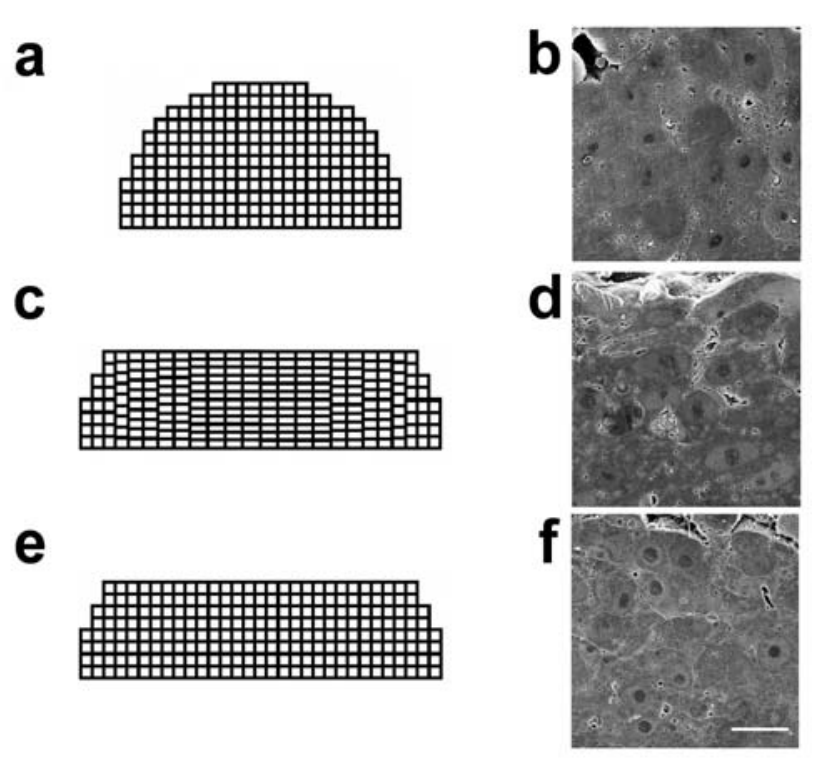

Fig. 3. Variations in individual cell shape during compression experiments. Schematic drawings show cross sections of half of the aggregate, (its top being in contact with the UC). a) uncompressed, c) and e) aggregates immediately after the compression and after the force relaxation, both under constant strain. Field emission scanning electron microscopy (FESEM) images for the three states (courtesy of Francoise Marga) show sections about $50 \mu \mathrm{m}$ into the aggregate, perpendicular to the compression axis, close to the periphery of the aggregates. 
Fig. 3 shows shape changes of individual cells during force relaxation. The schematic representation illustrates that immediately after the compression a pressure gradient is set up; cells towards the middle of the aggregates are deformed stronger than those close to the boundary due to their larger number on the vertical axis. FESEM images reveal that even if the initially spherical (circular in 2D) cells (b) are strongly deformed by compression (d), by the time equilibrium is reached they regain their precompressive shape (f). These results are consistent with earlier findings [19], where compression of aggregates was achieved by centrifugation. Since the number of cells, thus aggregate volume practically does not change during the 1 hour compression; the surface area of the aggregate can increase only by translocation of cells from the bulk to the periphery.

\section{Strength of cellular adhesion depends on the integrity of the cytoskeleton}

\section{Motivation}

According to the postulates of DAH, the liquid like behavior requires type dependent cell adhesion apparatus via cell adhesion molecules (CAM's). The adhesive and cohesive interactions give rise to an apparent tissue surface tension $(\sigma)$, reflecting the cohesive properties of the tissue. This surface tension is proportional with the number of adhesive bonds $(\mathrm{N})$ formed by the CAM's and the strength or binding energy of these bonds $(\mathrm{J})$. Recent experiments using cells with different expression level of $\mathrm{N}$-cadherins confirmed a linear relationship between $\sigma$ and $N$ [10]. Most of cadherins are transmembrane proteins attached to the actin 
cytoskeleton and their adhesive capacity is impaired if this connection is damaged [20-22]. This implies that for a fixed number of cadherins loss of cytoskeletal integrity decreases $\mathrm{J}$, and implicitly, $\sigma$. We investigated the strength of cellular adhesion as a function of appropriately quantified integrity of the cytoskeleton.

\section{Experimental design and methods}

Spherical aggregates composed of $\mathrm{CHO}$ cells were prepared as previously described. The parallel plate compression apparatus used in this work to measure

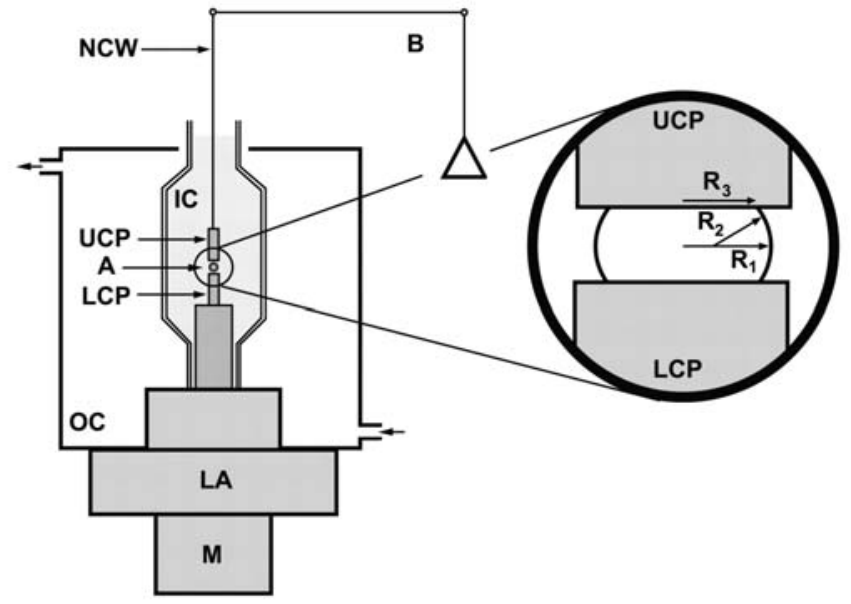

Fig. 4. Parallel plate compression apparatus used to measure tissue surface tensions. Inset: the geometric parameters of a compressed aggregate used for the evaluation of the surface tension.

liquid tissue properties is shown

in Fig. 4. Modified from previously used similar devices $[1,23]$, it is monitored by Labview software (National Instruments, Austin, TX) to record the entire force relaxation following the uniaxial compression of an aggregate between parallel plates. To minimize the adhesion of the aggregate to the plates, these were coated with poly(DTE co $7 \% \mathrm{PEG}_{1000}$ oxalate), (courtesy of Dr. Endre Szuromi from University of Missouri-Columbia). The poly(DTE co $7 \% \mathrm{PEG}_{1000}$ oxalate) was synthesized as described in [24], substituting the phosgene catalyzer with the less hazardous oxalyl-chloride. Structure and composition was confirmed with ${ }^{13} \mathrm{C}$ and ${ }^{1} \mathrm{H}$ NMR analysis and IR spectroscopy. 
A typical measurement was performed as follows. The initially spherical aggregate $(\mathrm{A})$ was placed on the lower compression plate (LCP) in the inner chamber (IC) filled with $\mathrm{CO}_{2}$ independent medium (maintained at $37{ }^{\circ} \mathrm{C}$ by a circulating water bath through the outer chamber $(\mathrm{OC})$ ) and rapidly compressed against the upper compression plate (UCP) by a stepping motor (M) (through the lower assembly (LA)), which was preprogrammed to produce a deformation of a definite magnitude. To avoid irreversible damage to the cells, aggregates were compressed maximum $30 \%$ of their original diameter. The relaxation of the compressive force (by measuring the apparent weight of the UCP with a CahnVentron (Cerritos, $C A$ ) electrobalance $(B)$, connected to the UCP through a nickelchromium wire (NCW)) was followed until it reached a constant equilibrium value, at which point the compression plates were separated, and the aggregate let to regain its original shape. Measurements in which the aggregate did not regain its precompressed shape where discarded. To assess the effect of the actin cytoskeleton on tissue liquid properties, surface tension measurements were performed with aggregates incubated in different concentration of latrunculin A (Molecular Probes, Eugene, OR) for 40 minutes, prior to compression.

\section{Data analysis}

The shape of the aggregate prior, during and after compressions was recorded by a Spot Insight CCD camera fitted to the horizontally positioned dissecting microscope. The surface tension was evaluated using the Laplace equation, $F_{e q} /\left(\pi R_{3}^{2}\right)=\sigma\left(1 / R_{1}+1 / R_{2}\right)$. Here $\sigma$ is the apparent surface tension (i.e. interfacial tension with the surrounding tissue culture medium), $F_{e q}$ is the equilibrium 
value of the compressive force, and $R_{3}$ is the radius of the circular contact area of the compressed aggregate with the plates. $R_{1}$ and $R_{2}$ are the radii of curvature of the aggregate's surface, respectively along its equatorial plane, and its peripheral contour (see inset in Fig. 4). The radii were determined by a Matlab - based custom tracking program, with an accuracy of $3 \mu \mathrm{m}$. The program traced the aggregate's contour on the basis of variation in gray scale values in its vicinity.

The force relaxation curves were accurately fitted with double exponential functions of the form $F_{e q}+A e^{-t / \tau_{1}}+B e^{-t / \tau_{2}}$ ( $F_{e q}, A, B$-constants), with two relaxation times, $\tau_{1}$ and $\tau_{2}$.

\section{Results}

Typical force relaxation curves for different latrunculin concentrations are plotted in Fig. 5. Earlier observations [1, 12] suggested a relaxation process with at least two characteristic timescales: aggregates subjected to brief compressions regain their shape almost instantly, whereas for prolonged compressions the aggregates recover their initial shape in a considerably longer time. Table 1 lists these two relaxation times we obtained from the fits.

\begin{tabular}{|c|c|c|}
\hline Latrunculin concentration $(\mu \mathrm{M})$ & $\tau_{1}(\mathrm{sec})$ & $\tau_{2}(\mathrm{sec})$ \\
\hline 0 & $8.6+0.42$ & $117.58+2.75$ \\
\hline 0.1 & $7.18+0.14$ & $106.39+1.99$ \\
\hline 0.2 & $5.35+0.16$ & $101.65+1.71$ \\
\hline 0.5 & $3.86+0.09$ & $85.53+1.13$ \\
\hline 1.0 & $3.78+0.18$ & $71.27+1.59$ \\
\hline
\end{tabular}

Table 1. Relaxation times obtained from the double exponential fits to curves shown in Fig. 5. 
The smaller of these accounts for the initial rapid relaxation due to the predominantly elastic response of cells to deformation (see also panels $c$ and $d$ in Fig. 3). The longer relaxation time reflects the slow, predominantly viscous response, in the course of which cells from the interior move towards the surface.

The relaxation of aggregates is accelerated with increasing latrunculin concentrations, as shown in Fig. 5.

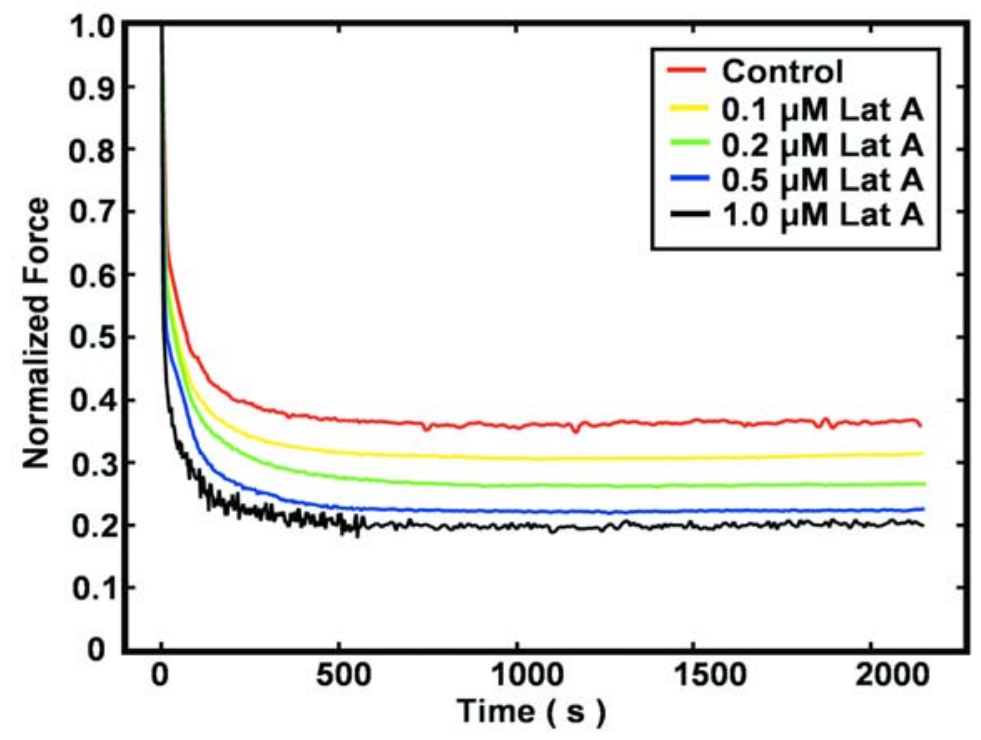

Fig. 5. Force relaxation upon compression of $500 \mu \mathrm{m}$ diameter spherical aggregates of $\mathrm{N}$-cadherin expressing $\mathrm{CHO}$ cells. Values along the vertical axis were normalized by the magnitude of the initial compressive force.

This indicates that our model tissue becomes progressively less viscous; it can flow easier and reach the post compressive equilibrium faster. Note that the relaxation times are proportional to the viscosity $[25,26]$.

The equilibrium forces at the end of the compressions together with the geometrical characteristics of the aggregate determine the tissue surface tensions $(\sigma)$, as described in the Data analysis. 
The dependence of $\sigma$ on the latrunculin concentrations is shown in Fig.6.

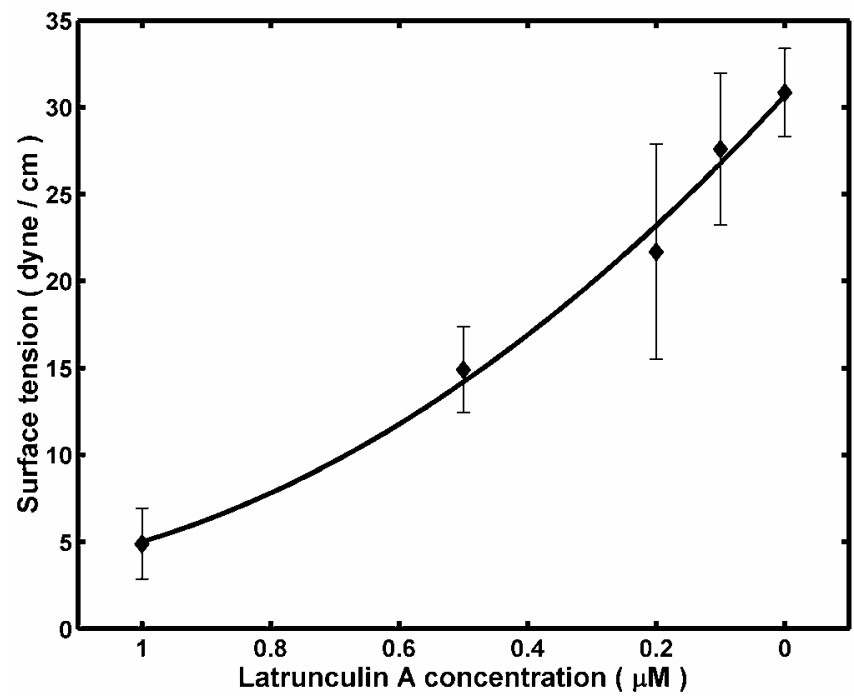

Fig. 6. Dependence of tissue surface tension on latrunculin concentration. Error bars indicate standard errors calculated from 8-12 compressions for each concentration. The line represents a quadratic fit of the data.

The figure shows that to a high accuracy $\sigma$ decreases quadratically with the latrunculin concentration. Since the number of cadherin molecules was fixed in these measurements, due to the above relationship between $\sigma$ and the strength of adhesive bonds $(J)$, these results imply that $J$ decreases also quadratically with latrunculin concentration.

\section{Conclusions}

The primary objective of the present work was to elucidate how the metabolically driven motion of individual cells can result in global liquid like tissue configurations. This was studied qualitatively by electron microscopy and quantitatively via a kinetic assay to observe the shape changes and assess the motile characteristics of individual cells during the compression of model tissue aggregates. Fluorescent labeling of cells allowed us to observe that upon compression all cells from the interior of the aggregates tend to migrate 
preferentially towards the periphery, similarly to liquid molecules. The outward displacements decrease toward the interior of the aggregate and saturate when the equilibrium is reached. The inward displacements can be attributed to cell insertions similar to the convergent extension encountered in embryonic development. Latrunculin treatment of the aggregates resulted in greater outward displacements near the surface compared with the control aggregates. Since compression took place in latrunculin free medium, this can be explained by the diminishing rate of diffusion of the drug from cells in the deeper regions of the aggregate and thus their decreased motility. Cells on the periphery regain their motility faster and try to accomplish the same surface area change as in the control aggregates. Thus the smaller number of motile cells requires larger displacements. Cells from the interior of the aggregate are still under the effect of latrunculin, they move in a random fashion, indicated by the comparable values of inward and outward displacements. The motility of cells is attributed to the actin cytoskeleton. Recovering from the latrunculin effect, its dynamic polymerization does not have a distinguished direction. Fig. 4 indicates that by the time the compressed aggregate reached postcompressive equilibrium, cells largely recovered from the initial deformation and regained their uncompressed shape.

Taken together, these results suggest that the increase in surface area is accomplished by the same mechanism as in true liquids: migration of subunits from the bulk to the periphery; tissues are analogous to liquids even on cellular scale; they change their area mostly by cell migration, rather then by variation in cellular shape. 
The second objective of this work was to employ the notion of tissue liquidity to generate quantitative molecular level information on cell adhesion. We attempted to relate surface tensions of model tissues to the integrity of the cytoskeleton, quantified in terms of latrunculin concentrations. Considering the earlier established relationship $\sigma=a_{1} J N$ [23], we found that $J=a_{2}+a_{3} C+a_{4} C^{2}$ $\left(a_{1}, a_{2}, a_{3}\right.$ and $a_{4}$ are positive constants, $\mathrm{C}$ is the latrunculin concentration). This result implies that diminished cytoskeletal integrity can be compensated by the upregulation of the number of active adhesive bonds or loss of adhesive bonds can be compensated by the re-establishment of cytoskeletal integrity.

Disruption of the actin cytoskeleton affects numerous cell functions. Cell motility requires polymerization of G-actin molecules into F-actin fibrils, pushing the leading edge in the direction of travel [27]. Latrunculin is the most specific drug known to target globular actin: molecules trap the actin monomers forming 1:1 complexes, thus making them unavailable to polymerization. This process is reversible: once the drug is removed, cells regain their shapes, and consequently their motility. As far as the ability of tissues to respond to deformations is concerned, damage to the actin cytoskeleton leads to two competing mechanisms. Decoupled from the cytoskeleton, cell adhesion molecules possess a smaller binding energy, the cells adhere less to each other, and thus they move easier within the tissue. On the other hand, cells loose their actin driven motility. In the first case the apparent tissue viscosity decreases, in the second one, it increases. Both of these effects are present in our post-compressed aggregates. Cells on the surface of the aggregates recover from the latrunculin treatment first, thus they regain their 
motility faster. Cells in the interior of the aggregates do not participate in the relaxation process due to their loss of motility. With increasing latrunculin concentrations the postcompressive relaxation is more rapid, indicated by the decreasing relaxation times (see values in Table 1). In all the compression experiments the aggregates regained their initial shape, another indication of cell motility.

It has been amply demonstrated that mechanical stresses induce changes in the cells' molecular composition. Mechanical forces modify and regulate various cell functions, such as differentiation, proliferation [28], gene expression [29-31] and signal transduction $[28,32-36]$. However, we believe these changes do not have an effect on the results obtained on cell motility and cohesion. The results represented in Fig. 2 indicate that in the absence of latrunculin all the cells in an aggregate participate in the relaxation, thus the deformation does not have an effect on cell motility. Recent experimental findings [10] established a linear relationship between tissue surface tension and number of cadherins per cell surface. The surface tension was assessed through similar compression studies, suggesting that the uniaxial deformation had no effect on cadherin expression, or affected all cell lines similarly.

In summary, we demonstrated that the analogy between tissues and ordinary liquids holds also on the cellular level, which may be used to interpret biological processes at various scales. Our results imply that the integrity of a tissue can be controlled in a compensatory manner by either the quantity of the adhesion molecules of its cells or by the integrity of their cytoskeleton. Such compensatory 
mechanisms may prove valuable in controlling epithelial-mesenchymal transitions, tumor metastasis or for tissue engineering applications.

Embriogenesis starts from a single cell, whose genetic code is executed, thus a highly complex living organism emerges: cell differentiation and division creates a variety of cell types, which then are organized into tissues that form the organs. This is accomplished by directed cell movements, thus tissue liquidity (the ability of the cells to flow) is a key ingredient in morphogenesis. The analogy of cell aggregates with liquid droplets led us to the idea to use cell spheroids whose controlled fusion could give rise to geometries encountered in a living organism. In the next chapter we explore this possibility and discuss the relevance of cell-cell and cell-extracellular matrix interactions giving rise to apparent interfacial tensions that drive the self assembly process. 


\section{Engineering biological structures of prescribed shape using self assembling multicellular systems}

\section{Background}

Self assembly is a fundamental process that drives structural organization in both inanimate and living systems, an autonomous organization of components, from an initial state into final pattern or structure without external intervention [37]. Histogenesis and organogenesis are examples of self-assembly processes, in which, through cell-cell and cell-extracellular matrix interactions, the developing organism acquires its final shape. In the present study we demonstrate how the self organizing properties of cells and tissues can be exploited to build three dimensional living biological structures of prescribed geometry, the ultimate goal of tissue engineering.

The term and concept tissue engineering is attributed to the bioengineering pioneer Y.C. Fung of the University of California San Diego. Used first in his proposal submitted to the National Science Foundation in 1985 and proposed again at a panel meeting NSF's Directorate for Engineering Bioengineering and Research to Aid the Handicapped Program in 1987; this emerging field drew scientists from various fields to gather at the first formal scientific meeting in 1988, at Lake Granlibakken, California. The review article by Joseph Vacanti and Robert Langer [38] defined tissue engineering as “... an interdisciplinary field that applies the

principles of engineering and the life sciences toward the development of biological substitutes that restore, maintain or improve tissue function." Three general 
strategies were identified for the creation of a new tissue: using isolated cells or cell substitutes in surgical procedures, embedding tissue inducing substances and implanting cells placed on or within matrices. Tissue engineering aims not only to create implantable organs but also to better understand the fundamental mechanisms and principles of biological organization in general and organogenesis in particular.

Recent studies suggested to use cell aggregates rather than individual cells as building blocks in tissue engineering. Cell aggregates have been successfully used to understand the principles of cell-cell [39] and cell-extracellular matrix [40] interactions, as well as cell sorting [1]. Rapid prototyping technology allowed creation of 3D tissue constructs by cell deposition in biocompatible hydrogels [41]. We suggest that cell aggregates may be used as droplets of bioink which upon embedding into scaffolds (i.e. the bioink) have the ability to fuse into 3D structures. Our propositions are based on recent technological advances in the bioprinting technology [42-44] combined with the concept of tissue liquidity, as discussed in the first part of this research summary. To test the feasibility of such a proposition, we used aggregates of genetically transformed cells with controlled adhesive properties and embedded them in gels of different chemical and mechanical characteristics, considering histologically relevant geometries. Our results demonstrate that contiguous aggregates under appropriate conditions defined by the cell-gel interactions fuse into structures of specified morphology. 


\section{Experimental protocols and materials}

\section{Cell aggregate preparation}

Cell aggregates were prepared according to the protocol described in the tissue liquidity studies. Brightfield and phase contrast microscopies were not suitable for imaging the fusion of embedded aggregates due to the opaqueness of some gels, thus all aggregates were made from cells transfected with histone attached yellow fluorescent protein. To visualize interpenetration of cells between adjacent aggregates and 3D tubular structures, the aggregates were stained with $\mathrm{PKH} 2$ and PKH26 (green and red) membrane intercalating dyes. These fluorescent markers do not influence the adhesive properties of cells, as revealed by cell sorting studies [1].

\section{Biocompatible hydrogels}

Agarose. 4\% agarose solution was prepared by dissolving UltraPure Low Melting Point Agarose (Invitrogen, Carlsbad, CA) in distilled water. At this concentration the agarose solution gels at $28-30^{\circ} \mathrm{C}$, excluding heat damage of the cells during embedding.

NeuroGel. Neurogel is a biocompatible porous poly[N-(2-hydroxypropyl) methacrylamide] hydrogel, kindly provided by Stephane Woerly (Organogel Canada, Quebec). This gel has been shown to provide optimal conditions for spinal cord repair [45, 46]; it contains Arg-Gly-Asp (RDG) fragments, a protein with affinity to integrins, a special class of cell-matrix adhesion molecules.

Collagen. Rat tail collagen Type I (Sigma-Aldrich, St-Louis, MO) was dissolved in $1 \mathrm{M}$ acetic acid. Ham's F12 medium was added to promote cell viability, 
then $\mathrm{pH}$ of the solution was adjusted to 7.0 with sodium bicarbonate and HEPES buffer solution. Depending on composition, this mixture gels at room temperature in a few minutes. To tune the cell-gel interaction, three concentrations were prepared, at $1.0,1.2$ and $1.7 \mathrm{mg} / \mathrm{ml}$ final concentrations.

\section{Embedding procedures}

NeuroGel disks of $10 \mathrm{~mm}$ diameter and $2 \mathrm{~mm}$ height were washed 3 times in DMEM to eliminate the storage medium. A $0.5 \mathrm{~mm}$ wide, $0.5 \mathrm{~mm}$ deep circular groove was cut into a disk, then filled with 10 contiguously placed aggregates. The groove was then refilled with gel to completely embed the aggregates. The structure was kept in incubator for 3 days at $37{ }^{\circ} \mathrm{C}$ and $5 \% \mathrm{CO}_{2}$ in a tissue culture dish containing $10 \mathrm{ml}$ of DMEM.

The gel-aggregate structures in agarose and collagen gels were created by placing a continuous ring of 10 aggregates or rectangular sheets of 25 aggregates on the top of a previously solidified gel layer, then covering with liquid gel that embedded the aggregates after gelation. The samples were incubated under the same conditions as described above.

\section{Imaging techniques}

Aggregate structures in transparent agarose and collagen gels were visualized on an Olympus IX-70 microscope with fluorescent attachment at $4 \mathrm{X}$ magnification, images were captured with a Nikon CoolPix 5000 digital camera. Phase contrast microscopy images were taken on the constructs embedded in collagen gels. 
Structures prepared in NeuroGel were washed in PBS solution then embedded in Tissue-Tek OCT Compound (Electron Microscopy Sciences, Fort Washington, PA). The samples were slowly cooled $\left(1{ }^{\circ} \mathrm{C} / \mathrm{min}\right)$ to $-20{ }^{\circ} \mathrm{C}$ in Nalgene freezing container, then cryosectioned on a Reichert $2800 \mathrm{~N}$ Frigocut cryotome (Reichert-Jung, Arnsberg, Germany), yielding 10-16 slices mounted on microscope slides. Slices were visualized by fluorescent microscopy.

\section{Results}

\section{Experimental realization of the 3D structure}

To study the feasibility of engineering $3 \mathrm{D}$ constructs of prescribed geometry we have embedded aggregates of living cells into biocompatible gels. The ability of
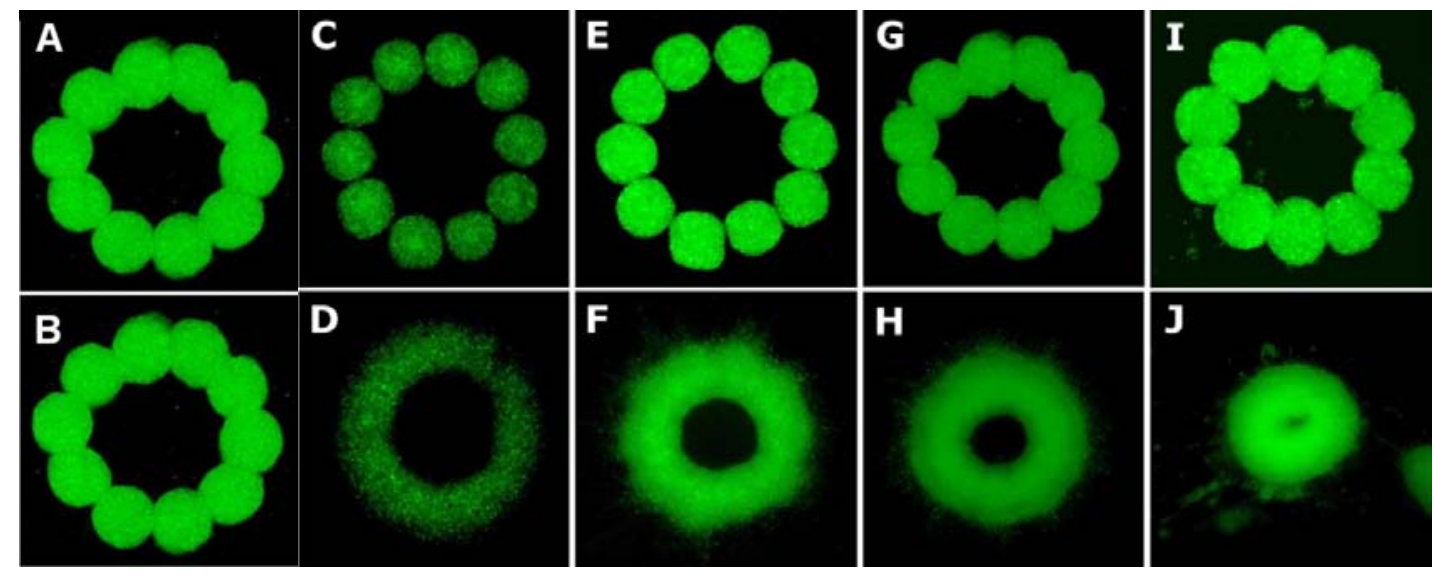

Fig. 7. Initial and final (upper and lower panels) cell aggregate configurations using various biocompatible hydrogels. Panels represent aggregates embedded in: $A-B$ agarose gel, $C-D$ NeuroGel; E-F, G-H and I-J collagen gels with $1.0,1.2$ and $1.7 \mathrm{mg} / \mathrm{ml}$ concentrations. The average diameter of an aggregate is $500 \mu \mathrm{m}$. Final images were recorded after 7 days. 
aggregates to fuse depends on the mutual properties of the cells and the gel. The results in Fig.7 support our predictions. We performed experiments with fixed cellcell adhesion and varying gel properties. For the purpose of this study we used Ncadherin transfected $\mathrm{CHO}$ cells and gels with different chemical compositions. Agarose represents a highly nonpermissive scaffold, cells do not interact at all with the environment, being unable to migrate into or reorganize the gel, and thus the initial and final configurations do not differ, the structure remains "frozen" in the initial state. Collagen 1.0 and $1.2 \mathrm{mg} / \mathrm{ml}$ as well as RGD containing NeuroGel match more the definition of the nonpermissive gel. These gels favor much less (collagen) or not

at all (NeuroGel), the dispersion of cells into the scaffold, thus facilitating fusion. A high concentration of collagen is analogous to a permissive environment, the cell-gel interactions dominate over the cell-cell ones, the construct tends to collapse into a single clump of cells, in striking analogy with the rounding-up behavior of irregular tissue fragments placed into a nonadhesive environment.

\section{The influence of the scaffold on 3D structure formation}

The above results demonstrate that scaffold properties affect cellular structures. The specific mechanism of how the gel influences pattern formation depends on its detailed chemistry, in general it is not easy to discern. 
It has been known that cells exert traction forces on their substrates and
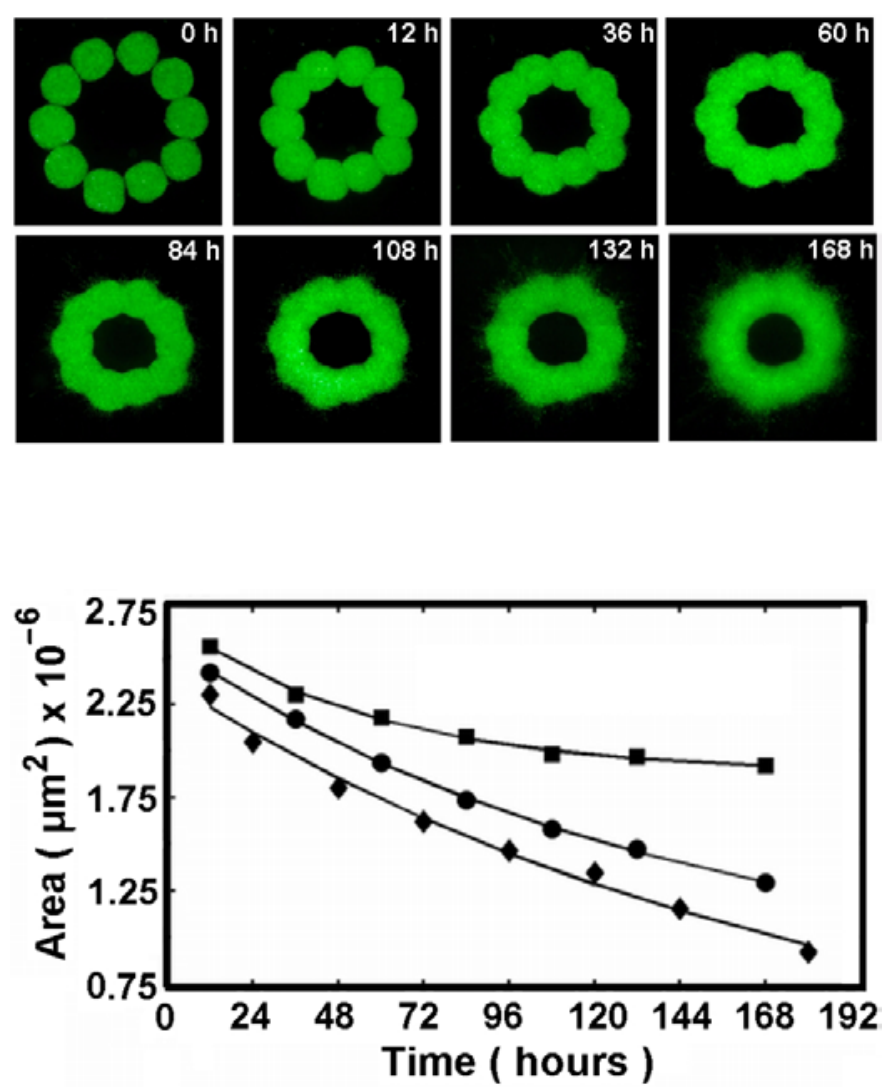

Fig. 8. Dynamics of gel contraction. Upper panel: Time lapse imaging of emerging toroid. Note that there are many more cells migrating into the gel (see Fig.9) than this image may suggest due to the weaker fluorescent signal of individual cells as opposed to that of the aggregates. Lower panel: quantification of contraction. Squares, circles and diamonds stand for 1.0, 1.2 and $1.7 \mathrm{mg} / \mathrm{ml}$ collagen concentrations. The relaxation time of the $1.0 \mathrm{ml} / \mathrm{ml} \mathrm{gel} \mathrm{is} 57$ hours from the exponential fit.

but not before (Fig. 9). The spikes or bundles of cells extend outside of the ring, suggesting that by this time a network of radially aligned collagen fibers has

Collagen has been a subject of numerous studies on this phenomenon [50, 52-55]. The pattern formation process in our case has some interesting features. As the fusion of the aggregates takes place, the ring of aggregates noticeably contracts, at least until approximately 60 hours (Fig.8). For higher concentrations of collagen the contraction is more dramatic, whereas for the nonpermissive agarose and NeuroGel no similar effects were observed. The contraction results from the $\mathrm{CHO}$ cells pulling on the collagen. At some point in the fusion process the pattern assumes a starburst appearance, noticeable at 60 hours

surrounding 3D matrices [47-51]. 
developed in the vicinity of the aggregates. (A study on this pattern formation was performed in [54]). In contrast, no similar effect is observed inside of the ring, not even at 144 hours (Fig.9). The probable reason collagen fibers do not align inside the ring is that the vectorial sum of the isotropically acting traction forces is zero. (An analogous cancellation makes the electric field in the interior of a conducting spherical shell to be zero.)

The contraction was quantified by measuring the area enclosed by the outer perimeter of the fluorescent ring. Curves represent exponential fits to the data of the form $A \exp \left(-t / T_{C G}\right)+B, A$ and $B$ being positive constants. The characteristic timescale of the contraction is defined by $\mathrm{T}_{\mathrm{CG}}$, approximately 57 hours for the $1.0 \mathrm{mg} / \mathrm{ml}$ collagen concentration, used in our analysis.

\section{Kinetics of aggregate fusion}

The transparency of the collagen allowed using brightfield microscopy to follow aggregate fusion. We defined as a measure of fusion the instantaneous value of the angle formed by two aggregates. Figure 9 shows the variation of the boundary between two adjacent aggregates for the $1.0 \mathrm{mg} / \mathrm{ml}$ collagen gel. Initially the angle between the tangents drawn to the joining point is zero, approaching 180 degrees when the fusion is completed. The curve is an exponential fit of the form C[1-exp(-t/ $\mathrm{T}_{\mathrm{CC}}$ )], with $\mathrm{C}$ positive constant and $\mathrm{T}_{\mathrm{CC}}=23$ hours, the characteristic timescale of the aggregate fusion. 

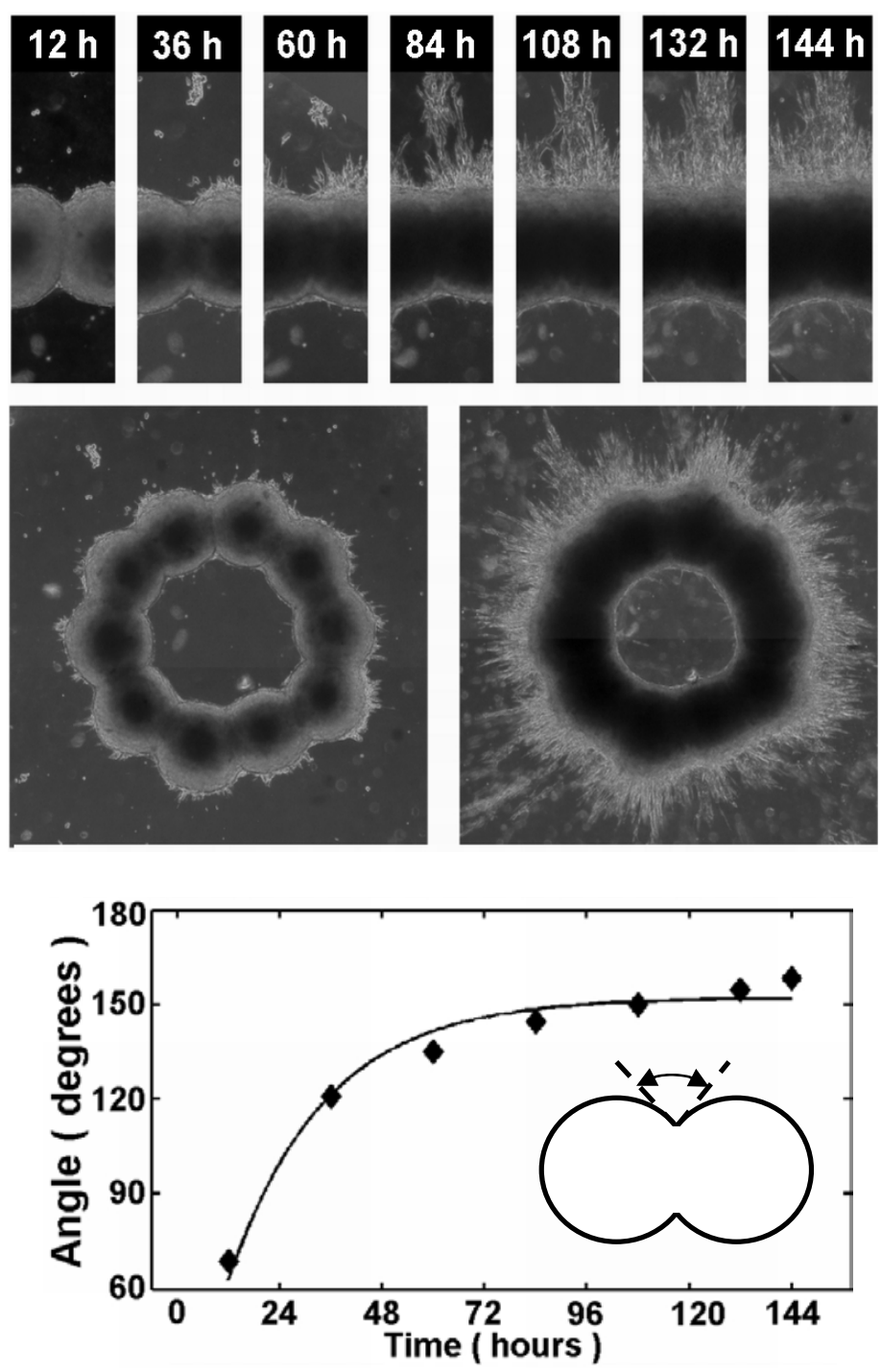

Fig. 9. Time course of aggregate fusion for the $1.0 \mathrm{mg} / \mathrm{ml}$ collagen concentration. Upper panel: Evolution of the cellular boundary between two adjacent aggregates. Schematics illustrate Note the exclusive radially outward movement at 60 hrs. Middle panel: the entire pattern at 36 (left) and 144 (right) hrs. Lower panel: Variation of the angle between two adjacent aggregates. Inset: angle measured between two tangential lines drawn to the point where the two aggregates join. 


\section{Optimization of fusion by the geometry of initial configuration: sheet}

\section{formation}

Structure formation in the previous experiments was restricted to contiguously placed aggregates in a circular pattern. This initial geometry does not affect the time evolution of the constructs, which is determined solely by the chemical characteristics of the gel, in other words, by the cell-gel interaction. We extended our

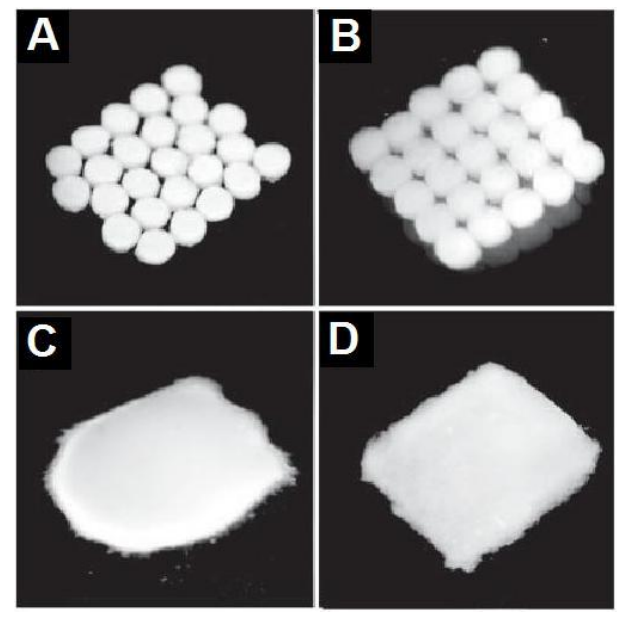

Fig. 10. Sheet formation depends on the initial configuration. Upper and lower panels represent initial and final configurations, respectively. Close packed structure $(A, C)$ fuses faster than the grid like pattern $(B, D)$ (data not shown), whose thickness varies even after 144 hours of incubation.

studies to two dimensional aggregate patterns in an attempt to create thick cellular sheets. Figure 10 shows two characteristic configurations, grid-like and close packed hexagonal arrangements. As expected, aggregates in the latter geometry fuse considerably faster, the emerging sheet has a uniform thickness overall.

\section{Fusion in three dimensions: cellular tube formation}

Our results on investigating the manifestation of tissue liquidity on cellular scale revealed that cell motility is responsible for the shape changes and force relaxations when spherical aggregates are subjected to uniaxial compressions. In the course of fusion experiments (see Fig. 8 and 9) we observed how the motility driven cell 
movements create shapes on the global scale. To study cellular rearrangements in the course of self assembly we embedded aggregates stained with red and green fluorescent dyes in $1.0 \mathrm{mg} / \mathrm{ml}$ collagen. Fig. 11(A-3) shows the outcome of the fusion process after $80 \mathrm{hrs}$. Confocal imaging on the fused construct revealed that the emerging ring-like pattern fuses due to the movement of cells across the boundary of two adjacent aggregates, and not only to the adhesion between the cells on the aggregate's surface.

Our motivation of building tubes originates from the fact that they represent a
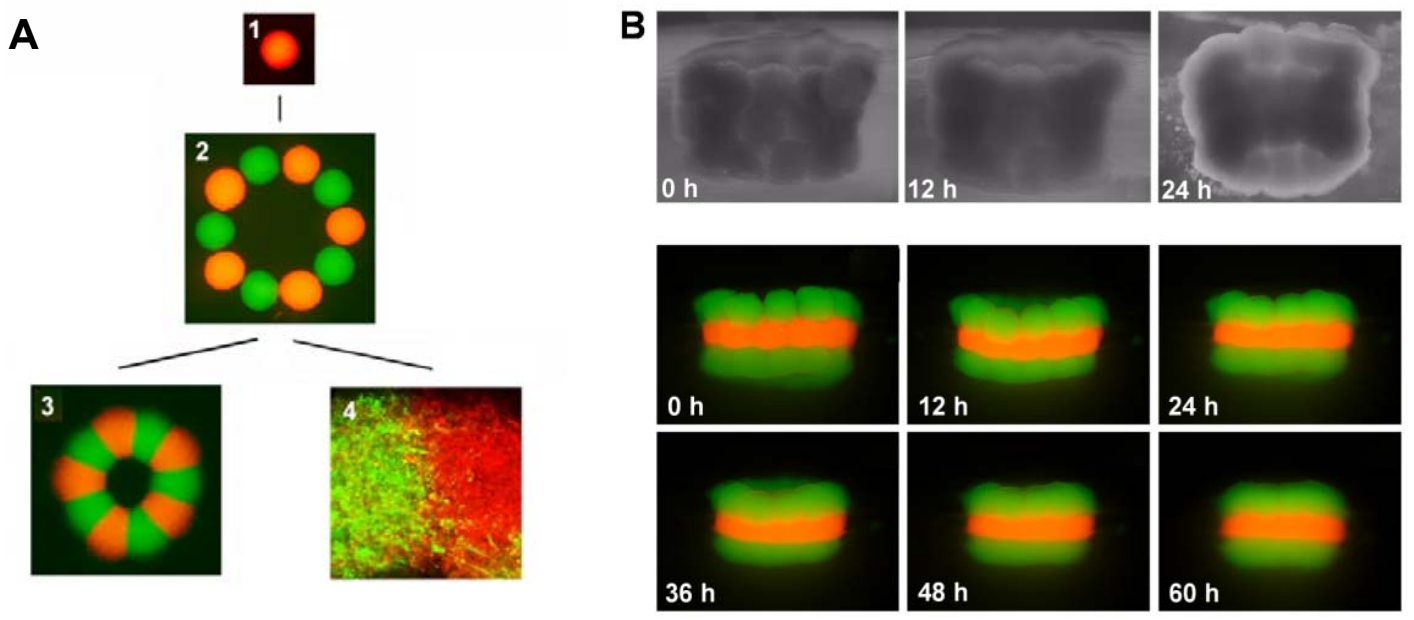

Fig. 11. (A) Outcome of the fusion of an initial ring (2) of contiguously arranged, fluorescent cell aggregates (500 um diameter) (1) in $1.0 \mathrm{mg} / \mathrm{ml}$ collagen (3). A configuration reached in 80 $h$ is shown. Confocal microscopy (40x magnification) (4) shows the details and extent of cell movement across aggregate-gel and aggregate-aggregate boundaries during the fusion of neighboring spheroids. (B) Bright field (upper panel) and fluorescent images (lower panel) of the time sequence of tube formation in the $1.0 \mathrm{mg} / \mathrm{ml}$ collagen gel with three closely packed rings of $\mathrm{CHO}$ cell aggregates.

fundamental unit of organ design. A living organism contains a variety of tubular structures with different cellular compositions and functions, as vasculature, intestines, lung, kidney, etc. Based on the optimal results on toroid formation (see 
Fig. 7) we built a short tube from $\mathrm{CHO}$ cells consisting of three layers of 10 aggregates each, embedded in $1.0 \mathrm{mg} / \mathrm{ml}$ collagen gel. We used the different fluorescent staining of the layers to visualize the fusion in the vertical direction. Figure 11B shows brightfield and fluorescent images of the evolution of the tubular construct. Beside the radial contraction of the tube (see Fig.8), time lapse imaging revealed the axial shrinking, which ceases after 48 hrs.

\section{Conclusions}

We have created simple but nontrivial structures (rings, sheets and tubes) by manually embedding spherical aggregates containing thousands of cells with specific adhesive properties. We have shown that under optimal conditions the contiguous aggregate structures fuse into two and three dimensional constructs, the fusion taking place in both horizontal and vertical directions, forming thick sheets and lumenous organ like modules.

The ultimate goal of these experiments was to demonstrate that spherical cell aggregates can be used as building blocks in tissue engineering applications. With the development of rapid prototyping methods, combining dispensers and bioprinters already available [41], they can be used in the capacity of bioink.

The biophysical basis of bioink is tissue liquidity, a concept proposed by Steinberg [8]. The differential adhesion hypothesis provides the molecular foundation of tissue liquidity explaining the liquid like behavior as a consequence of tissue surface and interfacial tensions, generated by adhesive and cohesive interactions between the cells. The DAH implies that all tissue templates embedded in a medium to which adhere weakly will adopt a spherical final shape. However, by 
fine tuning the two relevant competitive interactions (cell-cell and cell-extracellular matrix, one can control the outcome of the fusion process. Our choice of model tissue was built from $\mathrm{CHO}$ cells with controlled adhesive properties, i.e. fixed number of $\mathrm{N}$-cadherin molecules, therefore the chemical and mechanical characteristics of the gel was the only accessible parameter to control pattern formation. Nonpermissive gels (i.e. in which the cell-gel interactions were small in comparison with the cell-cell ones) do not allow or stop the evolution of the constructs, whereas in gels where cell-gel affinity dominates, the structures collapse into a single sphere of tissue, analogous to the rounding up experiments described in the previous chapter. The tissue structures can be trapped into long lived intermediate states by finding an optimal balance of these two interactions, providing sufficient time to halt structure evolution by removing the embedding gel.

The composition of the bioink is not limited to only one cell type per cell aggregate. Organs contain multiple cell types; their final architecture is determined by physical mechanisms during morphogenesis. It has been shown experimentally $[1,56]$ and by computer simulations $[13,57]$ that pattern evolution in sorting is consistent with the predictions of the DAH: it is driven by the interfacial tensions. In vitro experiments with tissues that are neighbors in normal development demonstrated that when mixed, they sort and recover their in vivo physiological configuration.

The liquid properties of tissues are especially important in our study. In the course of development embryonic tissues must possess liquid properties, they must move to give rise to organs. It is quite likely that if structure formation is induced by 
the methods described here, aggregates of other cell types (in particular stem cells) will behave similarly to embryonic tissues.

Bioink in the form of cell aggregates offers several advantages. Cell aggregates are already small building blocks, their fusion creates immediately a three dimensional tissue. The shear number of several thousand cells (instead of individual ones) effectively reduces printing time, thus cell viability increases. The "multicolor" bioink containing more than one cell type opens the possibilities towards creating complex organ modules. Last but no least, aggregates delivered from micropipettes by pressure operated or positive displacement devices are more likely to survive the experimental manipulations. In contrast, inkjet based printers create harsh mechanical or thermal conditions that a single cell might not be able to survive.

Our experiments are based on the analysis of cell-gel interactions: the interfacial tensions determine the fusion of the aggregates. In the case of collagen the cells reorganize the matrix; when fusion is completed, the gel shows an anisotropic character as opposed to its homogenous initial state. Pattern evolution involves two mechanisms with two characteristic time scales. One characterizes the dynamics of the cell-gel interactions, determining how long it takes for the cells to reorganize the matrix ( $\mathrm{T}_{\mathrm{CG}} \approx 57 \mathrm{hrs}$ for the $1.0 \mathrm{mg} / \mathrm{ml}$ concentration), the other one is based on cell-cell interactions, setting the time required for the aggregates to fuse ( $\mathrm{T}_{\mathrm{CC}} \approx 23 \mathrm{hrs}$ for the same concentration). The interplay of these two interactions determines the final pattern: ${ }_{\mathrm{C} G} / \mathrm{T}_{\mathrm{CC}} \approx 2.5$ implies a considerably slower contraction 
than fusion; the ring has time to stabilize, as opposed to the $1.7 \mathrm{mg} / \mathrm{ml}$ concentration where the contraction dominates and continuously shrinks the ring.

The ideal hydrogel must promote cell survival and postprinting self assembly. On the basis of their gelation mechanism we distinguish thermoreversible $[58,59]$, photosensitive [60-62], and $\mathrm{pH}$ sensitive [63] gels, as well as gels sensitive to specific molecular entities $[64,65]$. Detailed characterization of composition and combination of materials together with their properties is necessary to adapt them to specific specific cell types.

In summary, we have demonstrated that closely packed cell aggregates can self organize into tissue constructs of different shapes. Such self assembly driven structural organization could be employed in the evolving technology of bioprinting. The post printing cell rearrangements are highly dependent on the embedding gel, the "biopaper", whose composition could be controlled by the gel chemist. Based on these results, the spherical cell aggregates can be considered as "bioink" due to their liquid like properties and are suitable for aggregate dispensing printers. 


\section{Organ printing: computer aided tissue engineering}

\section{Motivation}

Organ printing constitutes a novel approach in tissue engineering aiming to create living three dimensional tissue structures by a rapid prototyping method, cell aggregate printing. Engineering functional living tissue replacements is a time consuming process: even in optimal conditions with extensive knowledge on the properties of cells and scaffolds it involves harvesting and growing cell cultures, mixing or implanting them in biocompatible scaffolds, where self assembly creates the biologically relevant geometries, and finally, conditioning and maturation of the tissue. Computer aided deposition of living cells represents a solution for the timing issue; it offers precise patterning in a relatively short time.

The main goal of the present study is to demonstrate the feasibility of organ printing as an alternative to create tissue replacements. We have recently shown that the apparent liquid properties of tissues could be employed to build living structures of prescribed shape [66]. Investigating in detail cell-cell and cell-gel interactions we arrived to the conclusion that self assembly driven organization can be used in the evolving technology of organ printing. 


\section{The principle of bioprinting}

All printing technologies require a specific sort of ink and a substrate on which the output of the process is created. We introduce the concept of bioink and biopaper as the ingredients of the bioprinting technology. The sequence in fig.12

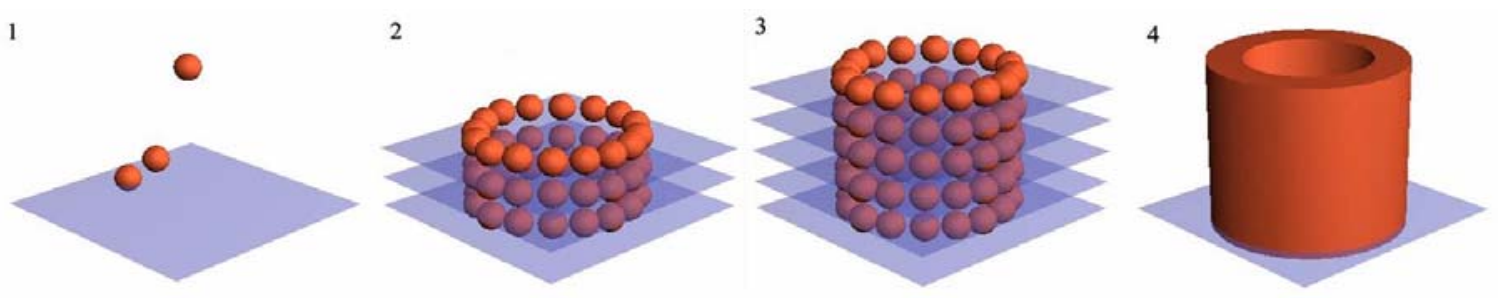

Fig. 12. The process of bioprinting. (1) Blue sheets represent biocompatible gel layers, red dots are cell aggregates. (2) Deposition proceeds layer by layer, the printed construct (3) fuses into a tubular structure(4).

illustrates the principle of bioprinting: layer by layer deposition of biocompatible hydrogel (the "biopaper") and spherical cell aggregates (the "bioink") to create three dimensional structures of prescribed geometry.

\section{The Bioink}

Spherical cell aggregates can be considered as bioink particles based on the liquid-like properties of cells and tissues. In suspension or on nonadhesive substrates various multicellular aggregates and tissue fragments round up into spherical shape in order to minimize their surface with the surrounding tissue culture medium, similarly to liquid droplets. The printing technology we adopted requires these droplets to be spherical and uniform, allowing their storage and accurate extrusion from printer cartridges. We designed and built specific devices capable of producing cell aggregates with reproducible diameter and shape. 


\section{The cell compactor}

Our model tissue aggregates in the organ printing project were built from genetically transformed $\mathrm{CHO}$ cells. These cells do not have the capacity to adhere to each other in their native state, therefore the only cell adhesion molecule they will express after retroviral infection are the $\mathrm{N}$-cadherins.

The size of the aggregate after rounding up in tissue culture medium is determined by the number of its constituent cells and the cellular density. To protect the calcium dependent cadherins we induced an excess of calcium by washing confluent $\mathrm{CHO}$ cultures with PBS containing $2 \mathrm{mM} \mathrm{CaCl}_{2}$. Cells were removed from the tissue culture dishes by treatment with ice cold $0.1 \%$ trypsin. The low temperature slows down the enzymatic activity, allowing more time to observe and control the enzyme reactions. Cell attachment was checked from time to time by pipetting the trypsin solution over the confluent layers. When cells started to detach in large continuous sheets (an indication of intact cell-cell versus diminished cellsubstrate adhesion), they were washed off from the surface of the dish with DMEM. The solution was centrifuged at 2000 RPM for 5 minutes, then the pellet was resuspended in 100-200 $\mu \mathrm{L}$ DMEM containing $2 \mathrm{mM} \mathrm{CaCl}_{2}$ and transferred in the cell compactor.

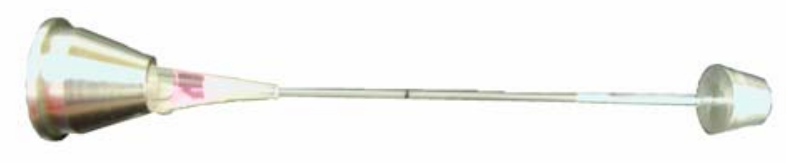

Fig.13. The cell compactor. The white cell mass in the tip of the pipette is packed tightly in the capillary tube by the centrifugal force.
The cell compactor (Fig. 13) consists of a metallic funnel holding a plastic pipette tip fitted with a $75 \mathrm{~mm}$ long capillary tube of $500 \mu \mathrm{m}$ inner diameter. Another 
metallic cone with a $2 \mathrm{~mm}$ long, $500 \mu \mathrm{m}$ diameter cylindrical extension on its base serves as a plug at the other end of the capillary. Upon assembly the compactor fits in a standard $15 \mathrm{ml}$ centrifuge tube. Centrifugation at 3-4000 RPM forces the cells to enter the tube and compact into a dense cellular "sausage" with uniform diameter and density. The capillary tubes containing the cells are then transferred in an incubator for 10-15 minutes to allow the reestablishment of cadherin bonds.

\section{The aggregate cutter}

Standardization of organ printing technology requires uniform bioink droplets. Preparation of aggregates from the cellular sausage by cutting them manually into cylinders of equal length produces inaccurate results, despite the experience and routine a researcher can develop over time. To address the uniformity issue we designed and built a computer controlled automated cell aggregate cutter, shown in fig.14.
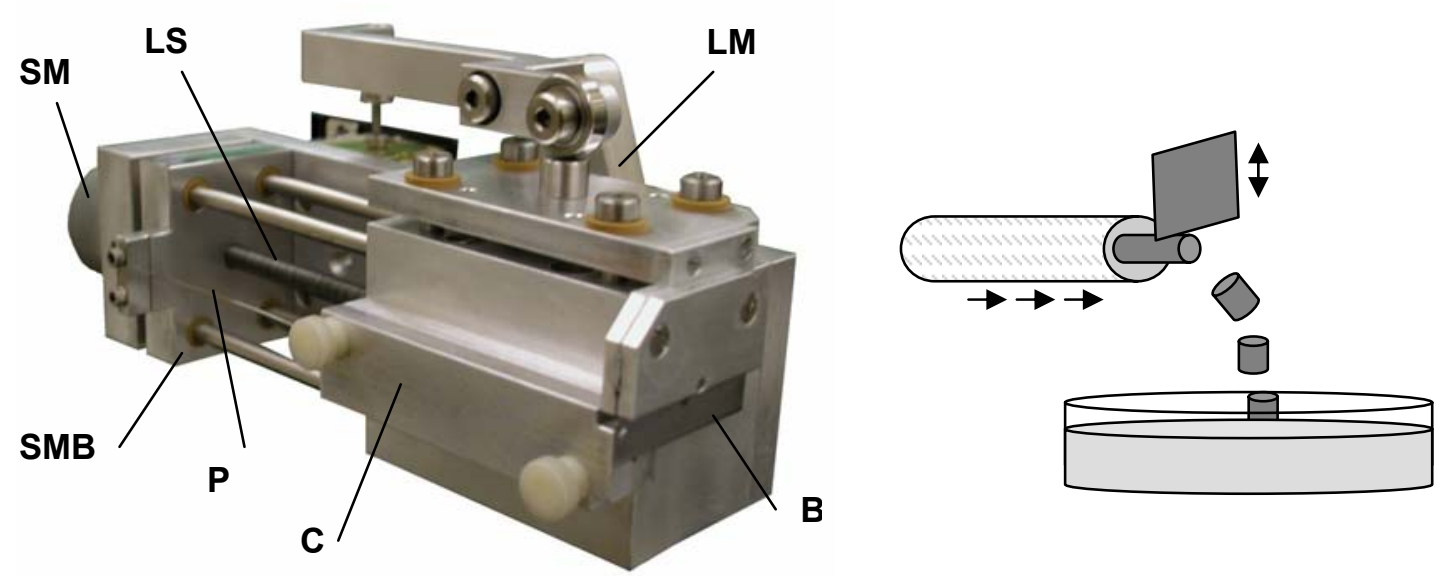

Fig.14. The aggregate cutter and its principle of operation. Abbreviations are explained in the text. 
The driving assembly consist of a stepper motor (SM) with 48 steps per turn coupled to the leading screw (LS), producing $20 \mu \mathrm{m}$ linear displacements per turn of the plunger $(P)$, attached to the sliding metallic block (SMB). The end of the plunger is introduced in a capillary tube housing the cellular "sausages" described earlier, which is secured by the cover $(C)$ with the two white plastic screws. The right panel in fig.14 presents the schematics of the cutting operation. The driving assembly produces a linear displacement equal with the diameter of the tube, extruding a 500 $\mu \mathrm{m}$ piece of cellular cylinder. When the extrusion stops, an electromagnetic coil not visible in fig. 14 activates the lever mechanism (LM) and blade (B), which cuts a cylindrical aggregate of equal diameter and height. To operate in physiological conditions, the blade is immersed in a pool of tissue culture medium, thus the fragments will collect on the bottom of the dish. The extrusion-cutting sequence is repeated until all of the cellular "sausage" is sliced up into aggregates. Transferred in special flasks with $3 \mathrm{ml}$ tissue culture medium, the fragments are rotated on a gyratory shaker at 120 RPM, where in 24-36 hours they round up into spherical cell aggregates (see fig.15, upper panels). This device produces 120-150 cylindrical aggregates in 3-4 minutes.

\section{The Cartridge}

The bioink droplets obtained by the protocol described above are transferred into the custom made cartridge, shown in Fig. 15. These cartridges are the same glass tubes used in the compactor and cutter, thus the cell aggregates will fit accurately into the capillary. (Aggregates with larger diameter would be distorted into 
ellipsoidal shape, while smaller ones would fall out from the tube during the printing process, rather than being extruded by the printer).
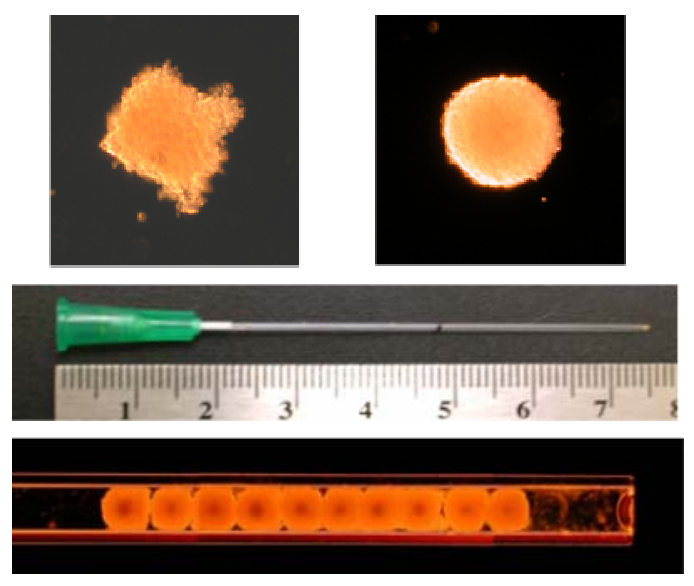

Fig.15. Upper panels: cylindrical fragment of $\mathrm{CHO}$ cells (left) rounds up into spherical cell aggregate (right). Middle: Capillary tube fitted with Luer-Lock needle socket. Lower: aggregates loaded contiguously into the cartridge.

\section{The Biopaper}

Biocompatible gels can be used either to promote natural regeneration by cell recruitment in vivo, or to serve as a supporting environment in creation of an artificial implantable tissue in vitro. In the first case the scaffold provides support in vivo, in the second one this support is provided until the cells are assembled and maturated enough to support themselves [67]. Chemical properties of the scaffold, pore size, biodegradability, cell-gel adhesion molecules, growth factors, immunoresponse and cytotoxicity are factors to consider in biocompatible gel design [68].

\section{Collagen}

The embedding experiments we performed in the previously described studies revealed that gels must provide an environment where tissue liquidity based self assembly can take place. The cell-gel interactions are tunable using different concentrations of collagen type I, an extracellular matrix abundant in the animal or human body. As collagen concentration increases, more and more gel fibers will be 
available for the cells use them as tracks for cell migration. Our results indicated that the $1.0 \mathrm{mg} / \mathrm{ml}$ concentration promotes the optimal formation of the desired geometry (See figures 7, 8, 9 and 11 for the aforementioned concentration).

\section{Gelatin and hyaluronan}

We suggested recently, that biological self assembly can be exploited to build living structures of prescribed shape [66]. The fusion process in our experiments resulted in a compact tissue sheet, a toroid or a tubular structure, depending on the initial pattern together with the optimal cell-gel interactions. Using cells of biological relevance instead of immortalized cell lines the emerging structure could be used in biomedical applications as tissue replacements or implants. Since these constructs are embedded in biocompatible hydrogels, they have to be removed prior their use from the surrounding scaffold. Removal by enzymatic digestion with collagenase is a slow process; collagenase can remove also the endogenous collagen secreted by the cells, thus modifying the properties of the fused tissue too.

Thermoreversible gels could be the ideal candidate in scaffold removal, since sol-gel and gel-sol phase transitions are temperature controlled. These gels are liquid below and solid above a specific temperature controlled by the chemical composition of the gel, thus when the desired shape of the tissue is attained, by simply lowering the temperature the gel flows away leaving behind the construct.

Tissues themselves can digest the surrounding gel by the activity of matrix metalloproteinases (MMP's). Studying the reorganization of extracellular matrices by glyoblastomas [69] we attempted to establish the key factors in the invasive behavior 
of brain tumor cells. We found a strong correlation between the activity of matrix metalloproteinases (MMP's) and cell-cell adhesion [69].

Gel degradation by enzymatic activity of cells offers another possibility worthy of investigation. We embedded cell aggregates of human umbilical smooth muscle cells (SMC, CRL2481, American Type Culture Collection, Manassas, VA) in different concentrations of thiolated gelatin, crosslinkable by a biocompatible polyvalent electrophyle, poly-ethylene-glycol-dimethyl-acrylate (PEGDA), provided by Dr. Glenn Prestwich, University of Utah, Salt Lake City, UT). Both gel and crosslinker were dissolved in F12K tissue culture medium containing 10\% FBS (U.S. BioTechnologies, Pottstown, PA), $0.03 \mathrm{mg} / \mathrm{ml}$ endothelial cell growth supplement

12

36

72
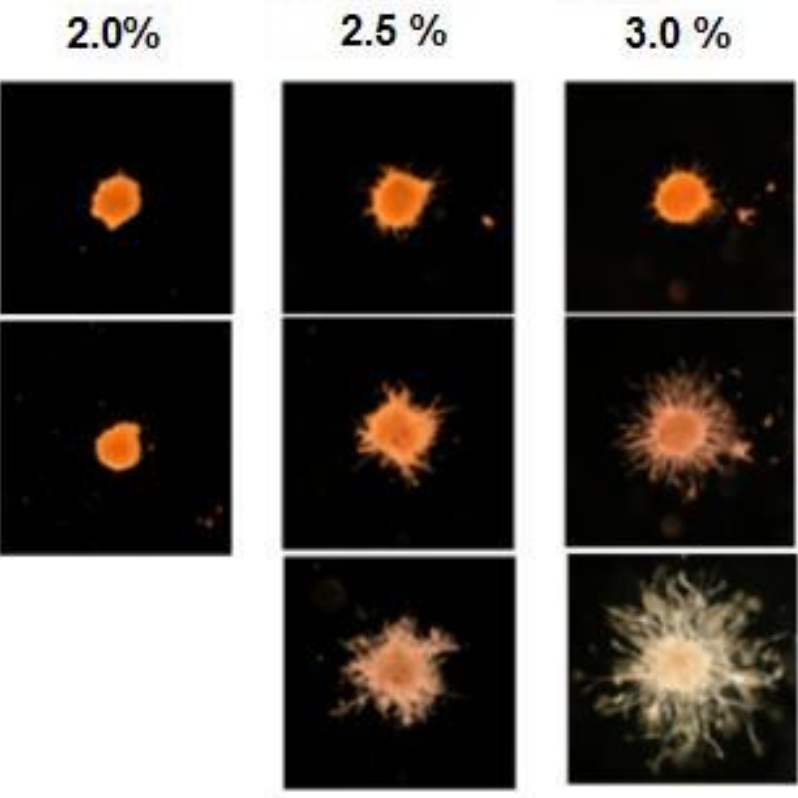

Fig.16. Time lapse studies of cell migration and gel degradation for the gelatin gels.
(Upstate, Charlottesville, VA),

\section{$0.1 \mathrm{mg} / \mathrm{ml}$ heparin (Sigma-}

Aldrich, St. Louis, MO) and 10

$\mu \mathrm{g} / \mathrm{ml} \quad$ Penicillin-Streptomicin

(Invitrogen, Carlsbad, CA). The

$4 \%$ PEGDA crosslinker was mixed in $1: 4$ ratios to the different gelatin solutions.

The results of the time lapse migration assays are shown in fig. 16. At $2.0 \%$ the gel does not favor cell migration; moreover, due to its 
self degradation and enzymatic effects from the SM cells, it detaches from the substrate and dissolves into the medium, releasing the aggregate in approximately 48 hours. At higher concentrations (2.5 and $3.0 \%$, respectively) the degradation is slower, the migration pattern is similar to the $\mathrm{CHO}$ cells - collagen experiments, cells reorganize the matrix and migrate radially outward. The migration increases with increasing concentration of gelatin content.

To find the optimal balance between cell-gel affinity and gel degradation, we

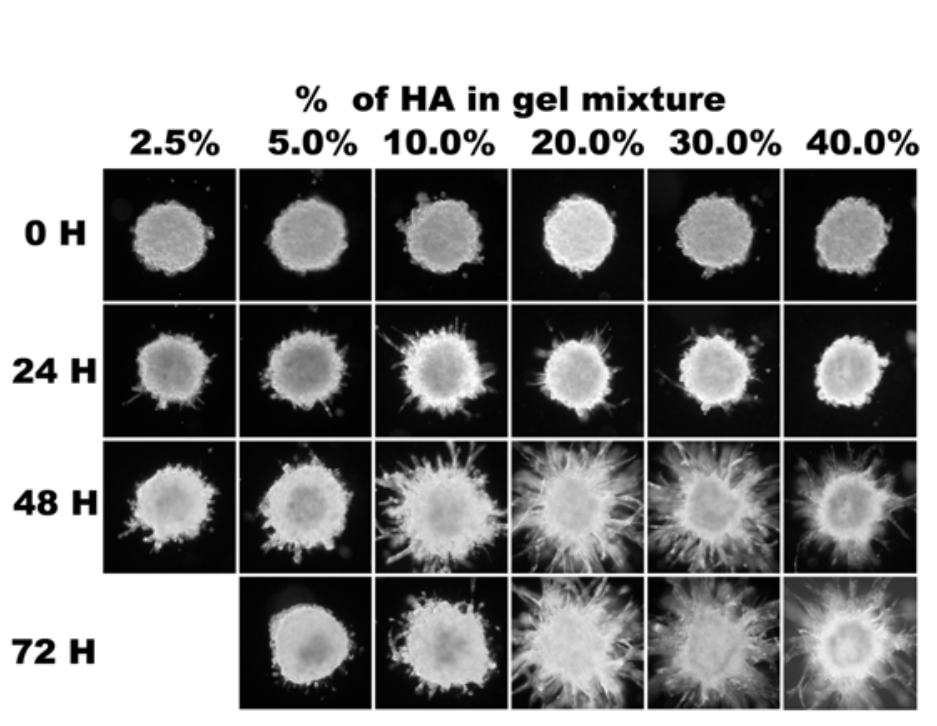

Fig.17. Interplay of cell-gel affinity and gel degradation.

prepared a mixture of thiolated gelatin and hyaluronan $(3 \%$ and $1.5 \%$ stock solutions, respectively). Both stock solutions were mixed with the same PEGDA crosslinker concentration and mixing ratio $(1: 4 \mathrm{vol} / \mathrm{vol})$, then combined into solutions with

$2.5,5,10,20,30$ and $40 \%$ (vol/vol) hyaluronan content. SM cells strongly adhere to the gelatin, and weakly or not at all to the hyaluronan. Since gelatin degrades considerably faster, than hyaluronan, the latter could provide a support for the construct for a longer time necessary to aggregate fusion. We found that $10 \%$ hyaluronan content stabilizes the gelatin gels and regulates cell migration in a favorable fashion (Fig.17). Gel invasion by SM cells starts at 24 hours, peaks at 
approximately 48 hours, than the gelatin degradation causes retraction of cellular projections, while hyaluronan still keeps together the gel-aggregate structure.

Our results suggest that the two competing mechanisms, fusion support for aggregate self assembly and gel degradation can be tuned to achieve three dimensional tissue construct with scaffold elimination at the end of the fusion process.

\section{The Bioprinter}

The bioprinter used in the organ printing project is a modified version of the Roland MDX-20 milling machine (Roland DGA Corporation, Irvine, CA), represented in Fig.18. Originally developed to create molds for the plastics industry, it consists of an $\mathrm{X}-\mathrm{Y}$ two dimensional table and a $\mathrm{Z}$ assembly, housing a drill or knife. Templates created in AutoCAD are sent to the machine, where the three dimensional movement coordinated with the cutting mechanism carves the negative image of the object into a block of plastic material, which ultimately will serve as a mold.

The cutting device was replaced with two linear displacement extruders available from Fishman Corporation (Fishman Corporation, Hopkinton, MA). The extruders can be fitted with three syringes of 3,10 and $30 \mathrm{ml}$ volume, capable of extruding increments of liquid anywhere between $0.5 \mu \mathrm{l}$ and $30 \mathrm{ml}$, depending on the application.

One extruder is reserved for the liquid biocompatible gel, whose temperature can be controlled by a water jacket mounted around the syringe and a peristaltic pump to regulate flow control of the heating/cooling medium. The second extruder is

mounted with a syringe and a plunger, which deposits the cell aggregates one by 
one. The volume increments were translated to linear displacements and calibrated precisely to extrude one aggregate at a time.

The control unit of the dispensers is connected to and operated by the printer. The coordinates of the aggregates are embedded in scripts written in RML-1 programming language and are sent to the printer's memory which synchronizes the three dimensional motion with the extrusion.

The $X Y$ stage is also temperature controlled to maintain the construct at physiological temperatures during the printing process or vary the temperature to accelerate gelation.
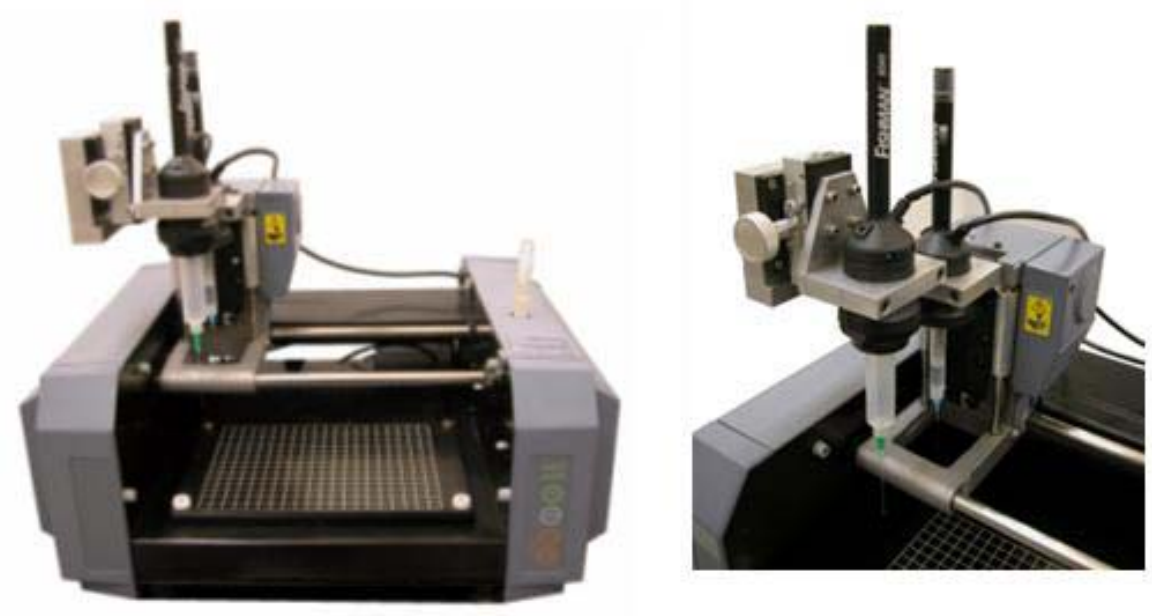

Fig. 18. The bioprinter and the extruders mounted on the $Z$ assembly. The dispensers can be moved relative to each other in the $Z$ direction to switch between gel and aggregate printing.

\section{The Bioprinting process}

Although there are many CAD based software on the market to operate the printer, none of them proved to be fully customizable to fit our specific needs in aggregate and gel dispensing. We created a user friendly application in Matlab 
programming language that, through specific functions, create scripts that calculate coordinates based on the input parameters and control data flow to the printer memory.

The software also offers a visual representation of the printing process, as
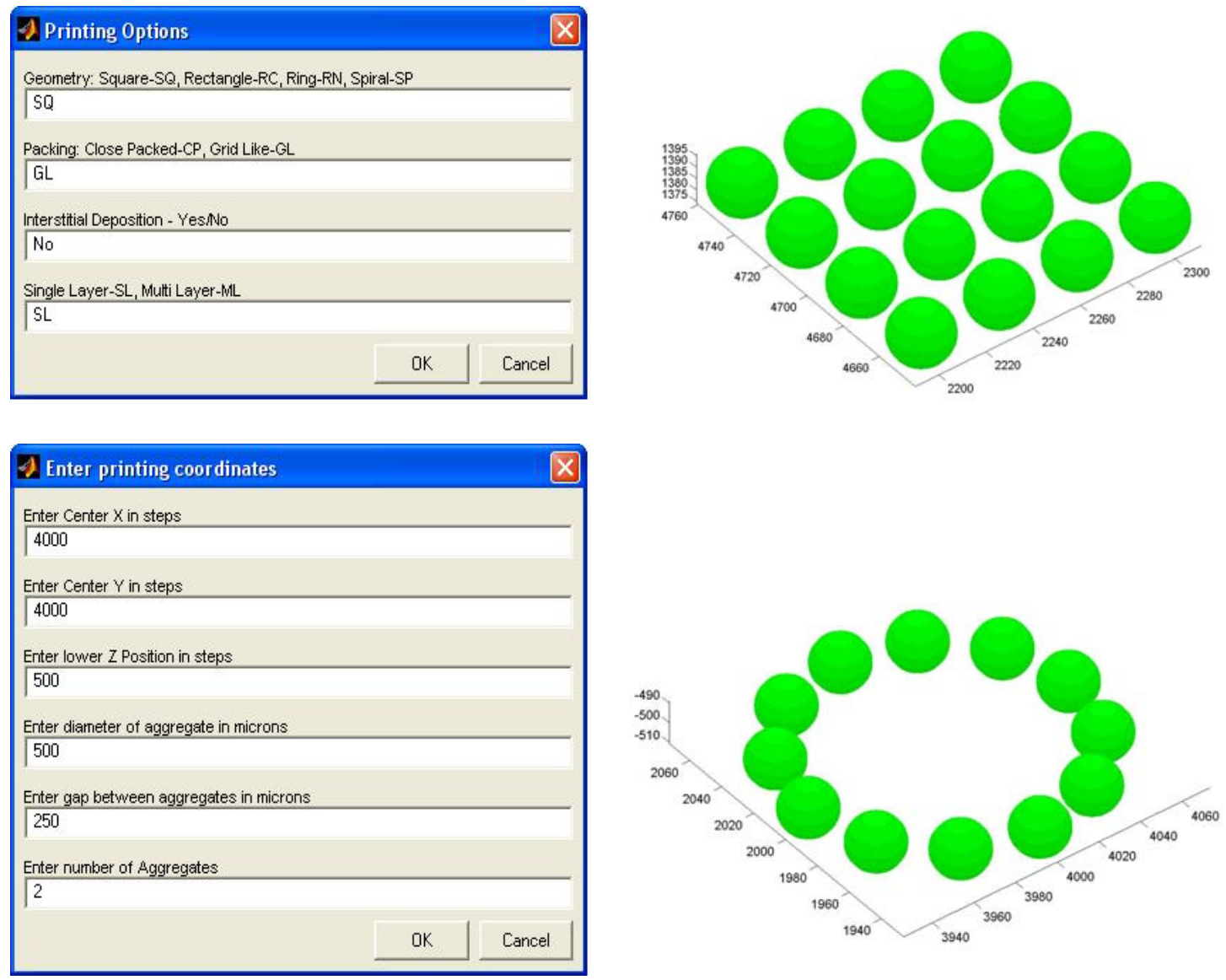

Fig. 19. Matlab based software for controlling the printer. Right panels: Printing options and parameter input dialogs determine the geometry of the construct and calculates the coordinates where the aggregates will be deposited. Right panels: "What you see is what you get"- the scripts create the $3 D$ data sent to the printer to create several initial configurations.

well as a feedback mechanism that corrects for the eventual errors arising from interfacial and meniscus effects when aggregates are extruded in the scaffold of choice. Fig. 19 shows snapshots of the dialog windows and visualization modules. 
We started to test the printing process with building basic structures as rings and sheets and squares of tissues. First, we deposited a liquid layer of $1.0 \mathrm{mg} / \mathrm{ml}$ collagen, that solidified in a few minutes in contact with the tissue culture dish heated up to $37{ }^{\circ} \mathrm{C}$ by the $\mathrm{XY}$ stage. The movie of the gel deposition is attached to this research summary (see supplementary material Gel.mov). When the first layer was close to the sol-gel transition we deposited a ring of $12 \mathrm{CHO}$ aggregates with $250 \mu \mathrm{m}$ separation. (In a pilot project under the University of Missouri-Columbia Research Experience Undergraduate program involving undergraduate mentoring we already demonstrated that two aggregates with less than an aggregate diameter separation reorganize the collagen bundles then migrate on these bundles towards each other. Since the collagen contracts over time (see results in fig. 8) this helps to further close the gap between aggregates). The process of aggregate deposition is demonstrated in the second supplementary material Ring.mov. 
The time-evolution of the printed patterns is consistent with the expected results (Fig.20).

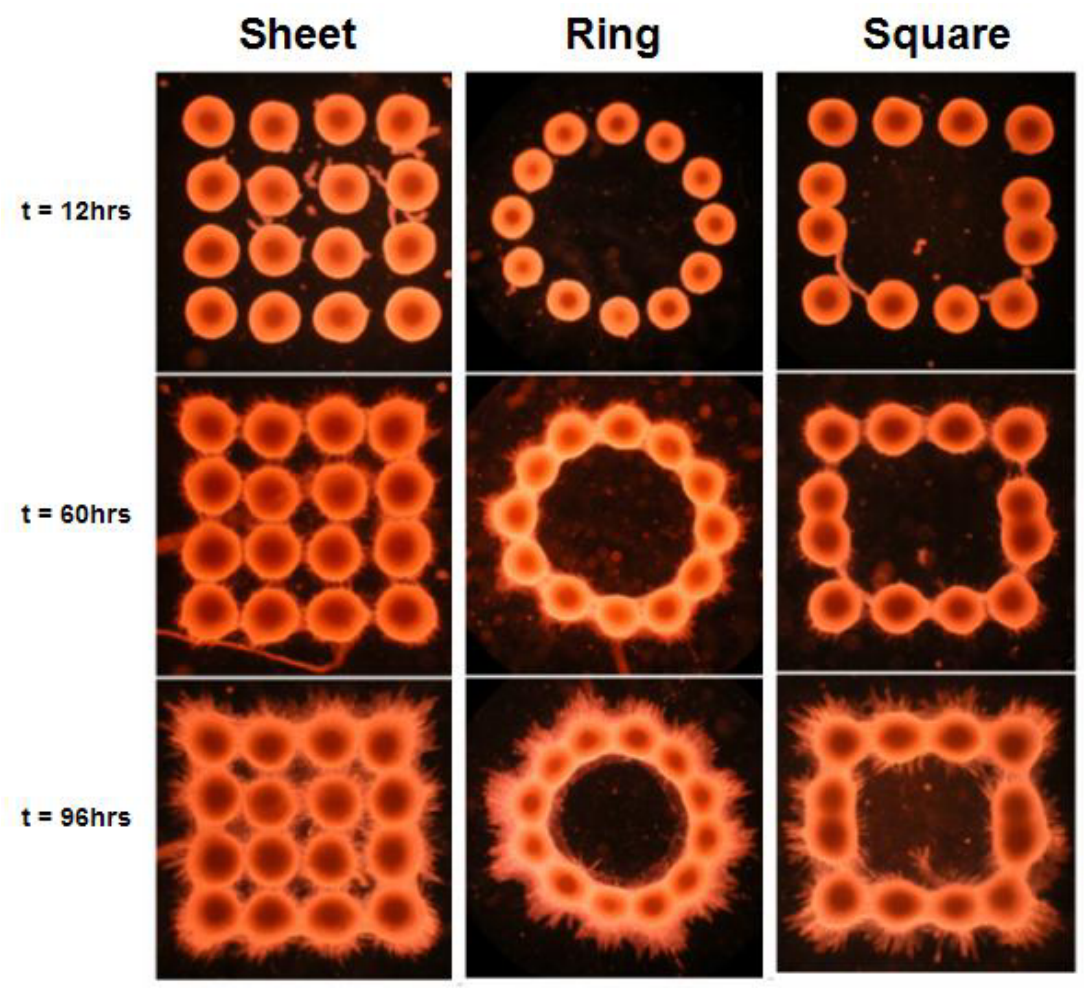

Fig. 20. Basic initial aggregate templates and their evolution in time.

Collagen gel concentration was $1.0 \mathrm{mg} / \mathrm{ml}$ in all cases.

\section{Functional living tissue structures created by bioprinting}

One of the main goals of tissue engineering is to create implantable biological constructs used in regenerative medicine. These artificial tissues are designated to repair or replace damaged tissue, or to restore function lost following an injury or disease. Design and use of such a tissue proves to be a highly complex task, usually accomplished by multidisciplinary teams dealing with various aspects of the preparation of the construct; chemical, molecular and physical characterization of the tissue to match the properties of the host environment; conditioning and 
maturation in bioreactors; implantation by a qualified medical team; as well as testing the integration and function of the newly created tissue construct.

Currently, cardiac tissue engineering is restricted to two major directions: implantation of cell-seeded scaffolds $[70,73]$ and injection of adult stem cells in damaged parts of the heart $[71,72]$. Due to the initial concentration of cells used in these experiments, manufacturing these tissue samples is a time consuming process, and it has its size limitations. We proposed to create a three dimensional tissue construct from cell aggregates by a novel method, the bioprinting, which fuses based on the liquid like properties of tissues and test the functionality as well as biochemical characteristics.

\section{Preparation of tissue constructs}

Atrio-ventricular tissue fragments from 9 day old Leghorn chicken embryos (courtesy of Brook Damon, University of Missouri-Columbia) were dissociated into single cells by incubation at room temperature for 5 minutes in $4 \mathrm{ml}$ of $0.05 \%$ Trypsin solution. The supernatant solution was transferred into centrifuge tubes and mixed with $2 \mathrm{ml}$ Fetal Bovine Serum to stop the enzymatic reaction, then it was centrifuged to retrieve single cells. This cycle was repeated by replacing the supernatant solution with fresh Trypsin until the fragments completely dissociated. The cells were plated in tissue culture dishes with $8 \mathrm{ml}$ of DMEM and allowed to grow until confluent monolayers formed. The tissue culture medium was replaced after one day in culture to remove the unattached red blood cells. Cell aggregates were prepared by the method described earlier, then embedded in $1.0 \mathrm{mg} / \mathrm{ml}$ collagen solution. After the 
gel solidified, the constructs were incubated in $3 \mathrm{ml}$ of DMEM for 5 days at $37^{\circ} \mathrm{C}$ with $5 \% \mathrm{CO}_{2}$ content in the incubator's atmosphere.

\section{Results and Discussion}

The cardiac myocytes used in our experiments are primary embryonic cells obtained from heart tissue fragments excised at 9 days of incubation. At this time point of embryonic development formation of the ventricles and septa is completed, the heart contracts periodically. Dissociation of such heart tissue yields in single cells, which, cultured under physiological conditions, regain their contractile property in approximately 3-4 days. The sparsely distributed individual cells beat at different frequencies until the culture becomes confluent and gap junctions form, yielding in synchronized contractions. The aggregate preparation protocol described earlier starts with a dense single cell solution, the primary cultures loose their contractile properties again; but since the cells are compacted into an aggregate, the beating resumes in approximately 2 days. Based on our previous results on cellular sheet formation, the cardiac myocyte aggregates fused into a compact sheet of $3 \times 3 \mathrm{~mm}$ area and $0.5 \mathrm{~mm}$ height.

Fig. 21 shows the initial configuration of aggregates and the final fused cellular sheets. Despite the grid like configuration, which proved to be not the optimal one (see Fig.10), the aggregates fused into a sheet of uniform thickness. This is due to the increased motility of embryonic cardiac myocytes, which, by their

nature are different than the immortalized $\mathrm{CHO}$ cell lines used in our proof of concept experiments. 

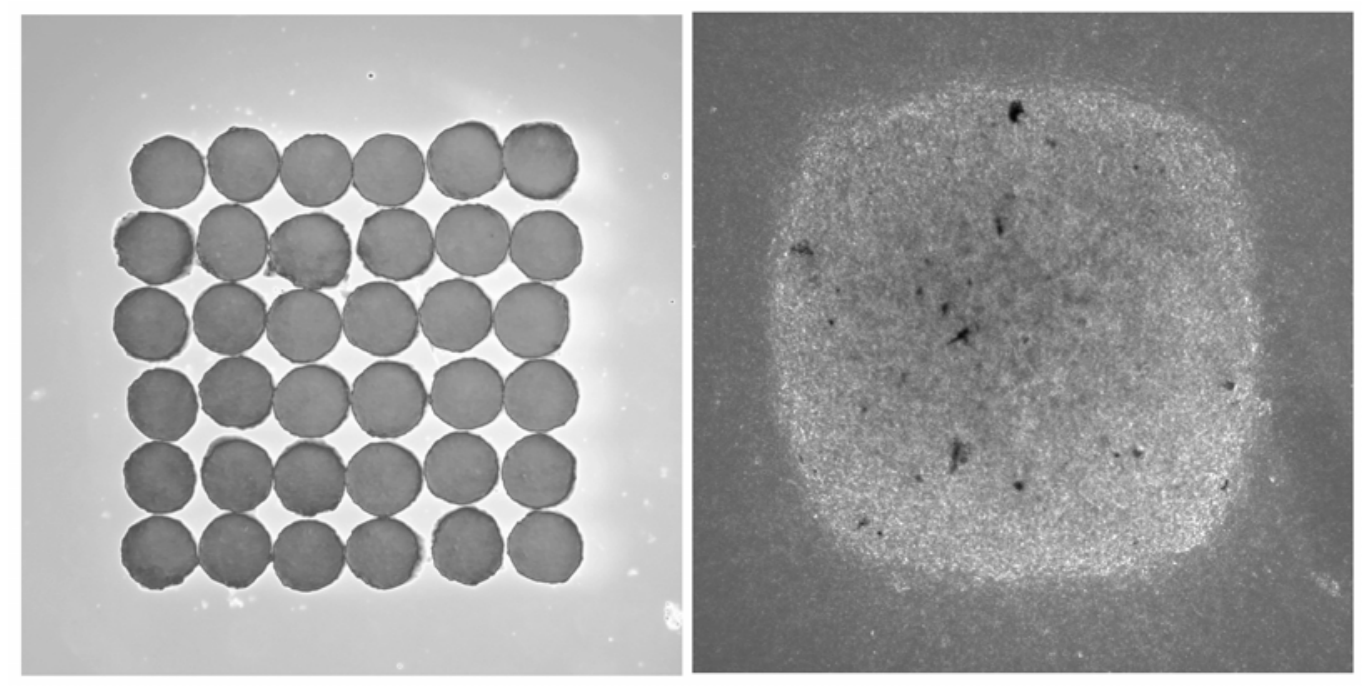

Cardiac Myocyte Contraction

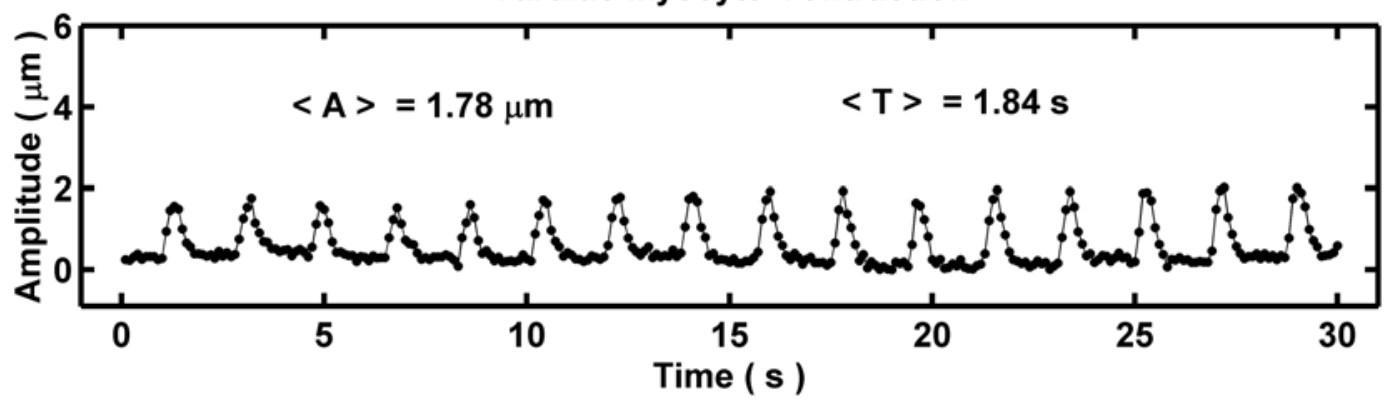

Fig. 21. Upper panels: Chicken cardiac myocyte sheet obtained by bioprinting. Left panel: Initial configuration of 36 aggregates. Right panel: fused and beating sheet after 5 days of incubation. Lower panel: amplitude and period of oscillations as determined from the contraction movies.

The emerging cardiac myocyte sheet shows a characteristic functionality of the heart tissue: it contracts periodically. Analysis of the supplementary movie (Cardiac sheet contraction.avi) allowed to determine the amplitude and period of the oscillations, $\mathrm{A}=1.78 \mu \mathrm{m}$ and $\mathrm{T}=1.84 \mathrm{~s}$, respectively. If the period of the oscillation falls in the normal range of heart contractions, the amplitude is limited by the extracellular milieu, in our case the collagen scaffold. 
The tissue samples we extracted from chicken embryos contained not only cardiac myocytes but also fibroblasts, the extracellular matrix being replaced by the collagen scaffold; therefore the construct has the right cellular composition. Using autologous cells removed from the healthy region of a diseased heart, such functional cardiac tissue sheets could be used as cardiac patches to restore functionality or replace damaged myocardium. The bioink particles of cardiac myocytes are already $500 \mu \mathrm{m}$ diameter blocks of tissue, and, combined with the rapid prototyping method we adopted, could result in sizeable functional heart tissue subject to implantation.

\section{Summary and future research}

The fundamental biological question on which these research topics are focused is to understand the self assembly during the organization of cells and tissues into functional organ modules. We investigated physical mechanisms and processes of cell rearrangements that shape the living organism during morphogenesis.

The major physical framework within which these processes were studied is the DAH based tissue liquidity, the concept according to which tissues mimic the behavior of viscoelastic liquids. This analogy has been amply demonstrated both in vitro and in vivo, measuring intensive physical parameters characteristic to the liquid phase on the global level. Our research went beyond the macroscopic scale of tissues and investigated in detail individual cell rearrangements on the cellular level. We demonstrated the manifestation of tissue liquidity on the cellular level (to our knowledge this has not been accomplished before) elucidating how the metabolically 
driven motion of individual cells can result in global liquid like tissue configurations. Studies on tissue cohesivity revealed that the integrity of a tissue can be controlled in a compensatory manner by either the quantity of the adhesion molecules of its cells or by the composition of their cytoskeleton.

We employed the concepts of tissue liquidity in an attempt to build three dimensional tissue constructs of prescribed shape. We investigated the interplay of cell-cell and cell-extracellular matrix interactions and concluded that adhesive and mechano-chemical properties of scaffolds are critical for fusion of model tissue aggregates. On the basis of our findings we proposed that cell aggregates could be used as self assembling bioink particles in the evolving technology of bioprinting.

The automated deposition of spherical cell aggregates in biocompatible gels constitutes a novel approach in tissue engineering. We modified existing printing devices to suit the needs of organ printing and created initial three dimensional aggregate templates in biocompatible gels that upon self assembly gave rise to tissue constructs of not only relevant geometries, but with functional characteristics too.

Future research plans include development of the hardware and software of the bioprinter to create more complex, functional tissue structures with a user friendly programmable interface and development of freeze-storage protocols for the bioink, an undergoing project with promising preminary results. 


\section{References}

1. Foty, R.A., et al., Surface tensions of embryonic tissues predict their mutual envelopment behavior. Development, 1996. 122(5): p. 1611-20.

2. Gilbert, S.F., Developmental Biology. 1991, Sunderland, MA: Sinnauer Assoc. Inc.

3. Trinkaus, J.P., Cells Into Organs: The Forces That Shape The Embryo. 2nd ed. 1984, Engelwood Cliffs, NJ: Prentice Hall.

4. Steinberg, M., Hierarchical order in the anatomical patterns established by heteronomic combinations of chick embryonic cells and tissues. Am. Zoologist, 1963. 3: p. 512.

5. Steinberg, M.S., On the Mechanism of Tissue Reconstruction by Dissociated Cells, III. Free Energy Relations and the Reorganization of Fused, Heteronomic Tissue Fragments. PNAS, 1962. 48(10): p. 1769-1776.

6. Steinberg, M.S., Reconstruction of tissues by dissociated cells. Some morphogenetic tissue movements and the sorting out of embryonic cells may have a common explanation. Science, 1963. 141: p. 401-8.

7. Trinkaus, J.P. and P.W. Groves, Differentiation in Culture of Mixed Aggregates of Dissociated Tissue Cells. PNAS, 1955. 41(10): p. 787-795.

8. Steinberg, M.S., Mechanism of tissue reconstruction by dissociated cells. II. Time-course of events. Science, 1962. 137: p. 762-3. 
9. Steinberg, M.S., On the mechanism of tissue reconstruction by dissociated cells. I. Population kinetics, differential adhesiveness. and the absence of directed migration. Proc Natl Acad Sci U S A, 1962. 48: p. 1577-82.

10. Foty, R.A. and M.S. Steinberg, The differential adhesion hypothesis: a direct evaluation. Dev Biol, 2005. 278(1): p. 255-63.

11. Steinberg, M.S., Does differential adhesion govern self-assembly processes in histogenesis? Equilibrium configurations and the emergence of a hierarchy among populations of embryonic cells. J Exp Zool, 1970. 173(4): p. 395-433.

12. Foty, R.A., et al., Liquid properties of embryonic tissues: Measurement of interfacial tensions. Physical Review Letters, 1994. 72(14): p. 2298-2301.

13. Glazier, J.A. and F. Graner, Simulation of the differential adhesion driven rearrangement of biological cells. Physical Review. E. Statistical Physics, Plasmas, Fluids, and Related Interdisciplinary Topics, 1993. 47(3): p. 21282154.

14. Mombach, J.C., et al., Quantitative comparison between differential adhesion models and cell sorting in the presence and absence of fluctuations. Physical Review Letters, 1995. 75(11): p. 2244-2247.

15. Godt, D. and U. Tepass, Drosophila oocyte localization is mediated by differential cadherin-based adhesion. Nature, 1998. 395(6700): p. 387-91.

16. Gonzalez-Reyes, A. and D. St Johnston, Patterning of the follicle cell epithelium along the anterior-posterior axis during Drosophila oogenesis. Development, 1998. 125(15): p. 2837-46. 
17. Hayashi, T. and R.W. Carthew, Surface mechanics mediate pattern formation in the developing retina. Nature, 2004. 431(7009): p. 647-52.

18. Spector, I., et al., Latrunculins: novel marine toxins that disrupt microfilament organization in cultured cells. Science, 1983. 219(4584): p. 493-5.

19. Phillips, H.M., M.S. Steinberg, and B.H. Lipton, Embryonic tissues as elasticoviscous liquids. II. Direct evidence for cell slippage in centrifuged aggregates. Dev Biol, 1977. 59(2): p. 124-34.

20. Gumbiner, B.M., Cell adhesion: the molecular basis of tissue architecture and morphogenesis. Cell, 1996. 84(3): p. 345-57.

21. Gumbiner, B.M., Regulation of cadherin adhesive activity. J Cell Biol, 2000. 148(3): p. 399-404.

22. Ozawa, M., M. Ringwald, and R. Kemler, Uvomorulin-catenin complex formation is regulated by a specific domain in the cytoplasmic region of the cell adhesion molecule. Proc Natl Acad Sci U S A, 1990. 87(11): p. 4246-50.

23. Forgacs, G., et al., Viscoelastic properties of living embryonic tissues: a quantitative study. Biophys J, 1998. 74(5): p. 2227-34.

24. Yu, C. and J. Kohn, Tyrosine-PEG-derived poly(ether carbonate)s as new biomaterials. Part I: synthesis and evaluation. Biomaterials, 1999. 20(3): p. 253-64.

25. Fung, Y.C., Biomechanics: mechanical properties of living tissues. 1993, New York: Springer Verlag.

26. Shaw, T., et al., Commonality of elastic relaxation times in biofilms. Phys Rev Lett, 2004. 93(9): p. 098102. 
27. Alberts, B., Johnson, A., Lewis, J.,Raff, M., Roberts, K., Walter, P.,, Molecular Biology of the Cell. 2002: Garland Science Publishing.

28. Pavalko, F.M., et al., Fluid shear-induced mechanical signaling in MC3T3-E1 osteoblasts requires cytoskeleton-integrin interactions. Am J Physiol, 1998. 275(6 Pt 1): p. C1591-601.

29. Davies, P.F., Flow-mediated endothelial mechanotransduction. Physiol Rev, 1995. 75(3): p. 519-60.

30. Komuro, I., et al., Mechanical loading stimulates cell hypertrophy and specific gene expression in cultured rat cardiac myocytes. Possible role of protein kinase C activation. J Biol Chem, 1991. 266(2): p. 1265-8.

31. Nakamura, T., et al., Mechanical strain and dexamethasone selectively increase surfactant protein $C$ and tropoelastin gene expression. Am J Physiol Lung Cell Mol Physiol, 2000. 278(5): p. L974-80.

32. Dolmetsch, R.E., et al., Differential activation of transcription factors induced by Ca2+ response amplitude and duration. Nature, 1997. 386(6627): p. 8558.

33. Gudi, S., J.P. Nolan, and J.A. Frangos, Modulation of GTPase activity of G proteins by fluid shear stress and phospholipid composition. Proc Natl Acad Sci U S A, 1998. 95(5): p. 2515-9.

34. Gudi, S.R., et al., Equibiaxial strain and strain rate stimulate early activation of G proteins in cardiac fibroblasts. Am J Physiol, 1998. 274(5 Pt 1): p. C1424-8.

35. Liu, M., A.K. Tanswell, and M. Post, Mechanical force-induced signal transduction in lung cells. Am J Physiol, 1999. 277(4 Pt 1): p. L667-83. 
36. Schmidt, C., et al., Mechanical stressing of integrin receptors induces enhanced tyrosine phosphorylation of cytoskeletally anchored proteins. J Biol Chem, 1998. 273(9): p. 5081-5.

37. Whitesides, G.M. and B. Grzybowski, Self-assembly at all scales. Science, 2002. 295(5564): p. 2418-21.

38. Langer, R. and J.P. Vacanti, Tissue engineering. Science, 1993. 260(5110): p. 920-6.

39. Steinberg, M.S., Adhesion in development: an historical overview. Dev Biol, 1996. 180(2): p. 377-88.

40. Ryan, P.L., et al., Tissue spreading on implantable substrates is a competitive outcome of cell-cell vs. cell-substratum adhesivity. Proc Natl Acad Sci U S A, 2001. 98(8): p. 4323-7.

41. Liu, V.A. and S.N. Bhatia, Three-dimensional photopatterning of hydrogels containing living cells. Biomedical Microdevices, 2002. 4(4): p. 257-266.

42. Boland, T., et al., Cell and organ printing 2: fusion of cell aggregates in threedimensional gels. Anat Rec A Discov Mol Cell Evol Biol, 2003. 272(2): p. 497502.

43. Mironov, V., et al., Organ printing: computer-aided jet-based 3D tissue engineering. Trends Biotechnol, 2003. 21(4): p. 157-61.

44. Wilson, W.C., Jr. and T. Boland, Cell and organ printing 1: protein and cell printers. Anat Rec A Discov Mol Cell Evol Biol, 2003. 272(2): p. 491-6. 
45. Woerly, S., et al., Reconstruction of the transected cat spinal cord following NeuroGel implantation: axonal tracing, immunohistochemical and ultrastructural studies. Int J Dev Neurosci, 2001. 19(1): p. 63-83.

46. Woerly, S., et al., Spinal cord repair with PHPMA hydrogel containing RGD peptides (NeuroGel). Biomaterials, 2001. 22(10): p. 1095-111.

47. Harris, A.K., D. Stopak, and P. Wild, Fibroblast traction as a mechanism for collagen morphogenesis. Nature, 1981. 290(5803): p. 249-51.

48. Harris, A.K., P. Wild, and D. Stopak, Silicone rubber substrata: a new wrinkle in the study of cell locomotion. Science, 1980. 208(4440): p. 177-9.

49. Vernon, R.B. and E.H. Sage, Contraction of fibrillar type I collagen by endothelial cells: a study in vitro. J Cell Biochem, 1996. 60(2): p. 185-97.

50. Vernon, R.B. and E.H. Sage, A novel, quantitative model for study of endothelial cell migration and sprout formation within three-dimensional collagen matrices. Microvasc Res, 1999. 57(2): p. 118-33.

51. Williams, A.F. and A.N. Barclay, The immunoglobulin superfamily--domains for cell surface recognition. Annu Rev Immunol, 1988. 6: p. 381-405.

52. Fray, T.R., et al., Quantification of single human dermal fibroblast contraction. Tissue Eng, 1998. 4(3): p. 281-91.

53. Korff, T. and H.G. Augustin, Tensional forces in fibrillar extracellular matrices control directional capillary sprouting. J Cell Sci, 1999. 112 ( Pt 19): p. 324958. 
54. Sawhney, R.K. and J. Howard, Slow local movements of collagen fibers by fibroblasts drive the rapid global self-organization of collagen gels. J Cell Biol, 2002. 157(6): p. 1083-91.

55. Shreiber, D.I., V.H. Barocas, and R.T. Tranquillo, Temporal variations in cell migration and traction during fibroblast-mediated gel compaction. Biophys $\mathrm{J}$, 2003. 84(6): p. 4102-14.

56. Davis, G.S., H.M. Phillips, and M.S. Steinberg, Germ-layer surface tensions and "tissue affinities" in Rana pipiens gastrulae: quantitative measurements. Dev Biol, 1997. 192(2): p. 630-44.

57. Graner, F. and J.A. Glazier, Simulation of biological cell sorting using a twodimensional extended Potts model. Physical Review Letters, 1992. 69(13): p. 2013-2016.

58. Jeong, B., et al., Thermogelling biodegradable copolymer aqueous solutions for injectable protein delivery and tissue engineering. Biomacromolecules, 2002. 3(4): p. 865-8.

59. Ohya, S., Y. Nakayama, and T. Matsuda, Thermoresponsive artificial extracellular matrix for tissue engineering: hyaluronic acid bioconjugated with poly(N-isopropylacrylamide) grafts. Biomacromolecules, 2001. 2(3): p. 85663.

60. Baier Leach, J., et al., Photocrosslinked hyaluronic acid hydrogels: natural, biodegradable tissue engineering scaffolds. Biotechnol Bioeng, 2003. 82(5): p. $578-89$. 
61. Elisseeff, J., et al., Transdermal photopolymerization of poly(ethylene oxide)based injectable hydrogels for tissue-engineered cartilage. Plast Reconstr Surg, 1999. 104(4): p. 1014-22.

62. Park, Y.D., N. Tirelli, and J.A. Hubbell, Photopolymerized hyaluronic acidbased hydrogels and interpenetrating networks. Biomaterials, 2003. 24(6): p. 893-900.

63. Kulling, D., et al., Poly-N-acetyl glucosamine: will it replace cyanoacrylate for treatment of gastric varices? A pilot study in a rabbit model. Endoscopy, 1998. 30(3): p. S41-2.

64. Hoffman, A.S., Hydrogels for biomedical applications. Adv Drug Deliv Rev, 2002. 54(1): p. 3-12.

65. Lutolf, M.P., et al., Synthetic matrix metalloproteinase-sensitive hydrogels for the conduction of tissue regeneration: engineering cell-invasion characteristics. Proc Natl Acad Sci U S A, 2003. 100(9): p. 5413-8.

66. Jakab, K., et al., Engineering biological structures of prescribed shape using self-assembling multicellular systems. Proc Natl Acad Sci U S A, 2004. 101(9): p. 2864-9.

67. Hutmacher, D.W., Scaffolds in tissue engineering bone and cartilage. Biomaterials, 2000. 21(24): p. 2529-43.

68. Tabata, Y., Recent progress in tissue engineering. Drug Discov Today, 2001. 6(9): p. 483-487. 
69. Hegedus, B., Marga, F., Jakab, K., Timms, K., Forgacs, G., The interplay of cell-cell and cell-matrix interactions in the invasive properties of brain tumors. Biophysical Journal, 2006 (Under review).

70. Shimizu T, YamatoM, Kikuchi A, Okano T: Cell sheet engineering for myocardial tissue reconstruction. Biomaterials 2003, 24:2309-2316.

71. Klug MG, Soonpaa MH, Koh GY, Field LJ: Genetically selected cardiomyocytes from differentiating embryonic stem cells form stable intracardiac grafts. J Clin Invest 1996,98:216-224.

72. Hassink RJ, Dowell JD, Brutel de la Riviere A, Doevendans PA, Field LJ: Stem cell therapy for ischemic heart disease. Trends Mol Med 2003, 9:436441.

73. Shimizu T, Yamato M, Isoi Y, Akutsu T, Setomaru T, Abe K, Kikuchi A, Umezu M, Okano T: Fabrication of pulsatile cardiac tissue grafts using a novel 3-dimensional cell sheet manipulation technique and temperatureresponsive cell culture surfaces. Circ Res 2002, 90:e40. 
VITA

Karoly Robert Jakab was born on December 18, 1974 in Tg-Mures, Romania. After graduating from the Bolyai Farkas high school with Mathematics Physics profile in 1993, he enrolled in the Physics Department of the Babes - Bolyai University in ClujNapoca, Romania. There he received his Bachelor's Degree in 1997, then obtained his Master of Science degree a year later in 1998. In 2000 he started his graduate studies in the Department of Physics \& Astronomy at the University of MissouriColumbia. He joined Dr. Gabor Forgacs's research group in July 2000 and received his Ph.D. degree in May 2006. He recently accepted a postdoctoral position at the University of Virginia-Charlottesville in Dr. Douglas DeSimone's laboratory, starting August 2006. 